
Université de Montréal

\title{
Parenting styles and adjustment in gifted children
}

\author{
par \\ Vassiliki Pilarinos
}

Département de psychologie

Faculté des arts et des sciences

Thèse présentée à la Faculté des études supérieures et postdoctorales

en vue de l'obtention du grade de Philosophiae Doctor (Ph.D.)

en psychologie

option générale

Juin, 2014

(C) Vassiliki Pilarinos, 2014 


\section{Résumé}

Cette recherche porte sur la problématique du développement psychosocial des enfants doués. Bien qu'il existe des travaux qui indiquent que les enfants doués souffrent plus souvent de problèmes d'adaptation que les autres, comme l'isolement social, la dépression, l'anxiété et une faible estime de soi, la littérature de recherche considère peu l'environnement familial des enfants doués comme étant un facteur qui puisse contribuer au niveau d'adaptation de l'enfant. La présente recherche a eu donc pour objectif de déterminer si les styles parentaux, tels que définis par Baumrind, sont associés à l'adaptation des enfants doués. Les styles parentaux des parents ont été mesurés à l'aide d'un questionnaire auto-rapporté. Le niveau d'adaptation d'un groupe d'enfants doués, âgés de 7 à 11 ans, a été évalué à l'aide de mesures de comportement et de concept de soi. La douance a été mesurée avec un test d'intelligence standardisé. Quarantehuit enfants doués et 52 enfants du groupe contrôle ont participé à l'étude. Les résultats ont démontré que les parents des enfants doués utilisent majoritairement un style parental démocratique. Les mères ont rapporté être significativement plus démocratiques que les pères. Les parents ont identifié un sous-groupe d'enfants doués ayant des problèmes sociaux avec leurs pairs, tandis que ces enfants doués et leurs enseignants n'en n'ont pas indiqué. Aucune association n'a été mise en évidence entre l'utilisation d'un style parental particulier et les problèmes sociaux chez les enfants doués. Cependant, l'utilisation du style parental autoritaire des mères a été associée à des problèmes de comportement moins élevés ainsi qu'un concept de soi intellectuel plus élevé chez les enfants doués. Inversement, le style parental démocratique des mères a été associé à des problèmes de comportements plus élevés chez les enfants doués. Le style parental permissif des mères a été associé à des niveaux de concept de soi moins élevés chez les enfants doués. Pour les pères, les styles parentaux autoritaires et permissifs ont été 
associés à des niveaux d'adaptation et de concept de soi moins élevés chez les enfants doués. Enfin, le niveau d'adaptation ainsi que les styles parentaux ont été comparés entre les deux groupes d'enfants. Les deux groupes ont présenté des niveaux d'adaptation dans la gamme de la normalité. De plus, les parents des deux groupes d'enfants ont rapporté des styles parentaux similaires. Pour les pères des enfants du groupe de contrôle, le style parental démocratique a été associé à des niveaux d'adaptation plus élevés. Le style parental autoritaire des mères et le style parental permissif des pères ont été associés à des niveaux de concept de soi moins élevés chez les enfants du groupe de contrôle. En somme, les conclusions de cette thèse permettent une meilleure compréhension de la complexité des liens entre les styles parentaux et l'adaptation des enfants doués.

Mots clés: adaptation, effets, concept de soi, enfant, douance, enfants doués, style parental 


\begin{abstract}
The present study examines the psychosocial development of gifted children. Although much evidence exists that gifted children experience problems of adjustment, such as social isolation, depression, anxiety, and low self-esteem, few studies have investigated the family environment of gifted children and its possible links to child psychosocial adjustment. The goal of this study, therefore, was to address these questions by examining the parenting styles, as defined by Baumrind, of parents of gifted children and their potential associations with the adjustment levels of their children. Parenting styles were measured using a self-report questionnaire. The level of adjustment for gifted children, aged 7 to 11 years old, was measured using behavioural and self-concept measures. Giftedness was determined using a standardized intelligence test. Forty-eight gifted children and 52 nongifted children participated in the study. Parents of gifted children reported using a predominantly authoritative parenting style. Mothers, however, reported significantly higher authoritative scores than fathers. Parents reported several gifted children to experience problems with peers, but their teachers did not report this nor did the children themselves. No associations were found between a particular parenting style and the reported presence of peer social problems in gifted children. Mothers' authoritarian parenting style was significantly associated with lower conduct problem levels, and higher intellectual selfconcept levels in gifted children. As for mothers' authoritative parenting style, a significant relationship was found with higher conduct problem levels in gifted children. Mothers' permissive parenting style was found to be associated with lower self-concept levels in gifted children. As for the fathers, authoritarian and permissive parenting styles were found to be linked to lower adjustment and self-concept levels in gifted children. Adjustment levels and parenting styles were also compared between gifted and nongifted children. For both groups of children,
\end{abstract}


adjustment levels were in the normal range and the parents reported similar use of the three parenting styles. As for the relationships between parenting styles and adjustment in nongifted children, fathers' authoritative parenting style was found to be associated with higher child adjustment levels. Mothers' authoritarian and fathers' permissive parenting styles were found to be associated with lower self-concept levels in nongifted children. The conclusions of this thesis permit a better understanding of the complexity of the links between parenting styles and the psychosocial adjustment of gifted children.

Key words: child adjustment, child outcomes, self-concept, giftedness, gifted children, parenting styles, parenting 


\section{Table of Contents}

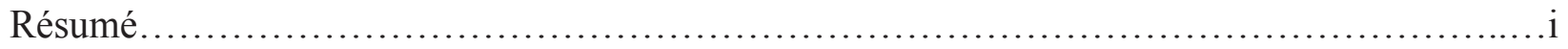

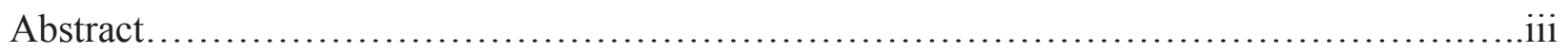

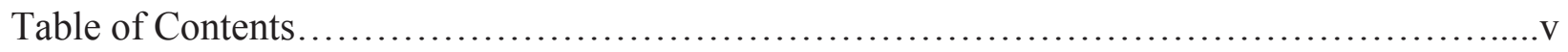

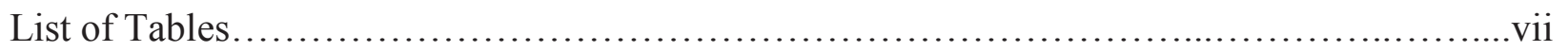

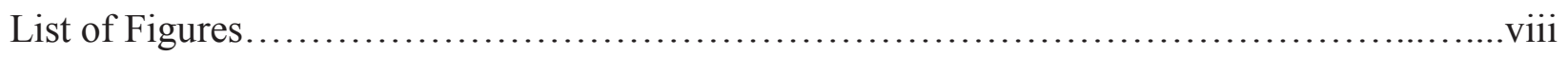

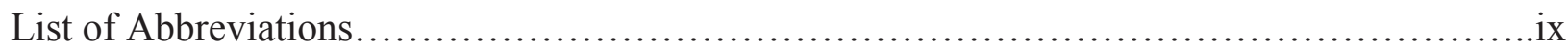

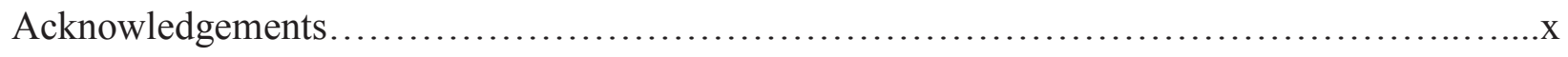

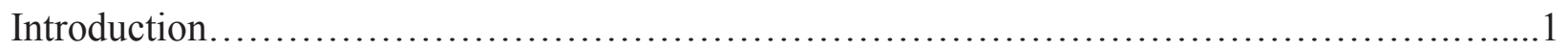

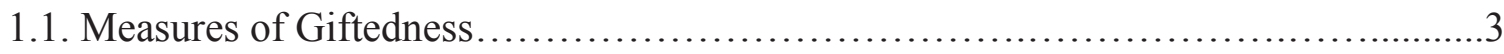

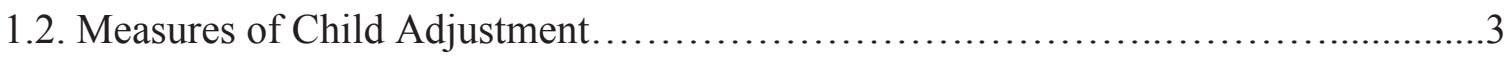

1.3. Gifted Child Adjustment...................................................... 5

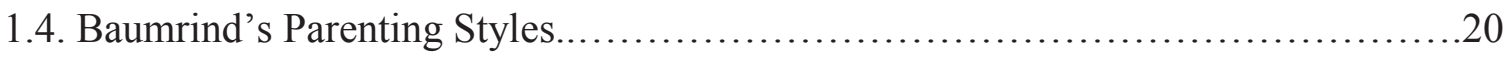

1.5. Parenting and Gifted Child Adjustment..........................................23

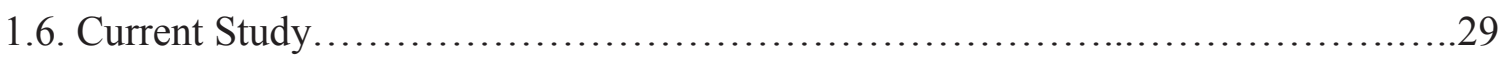

1.7. Research Objectives......................................................... 30

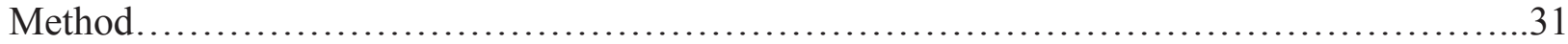

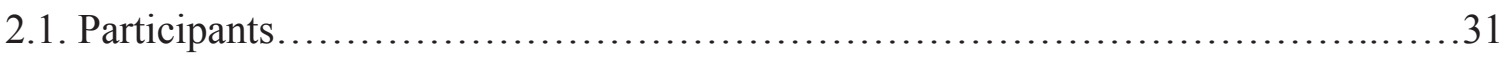

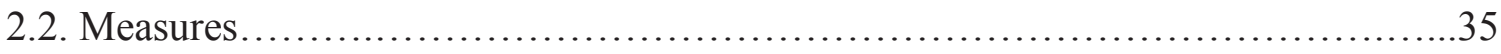

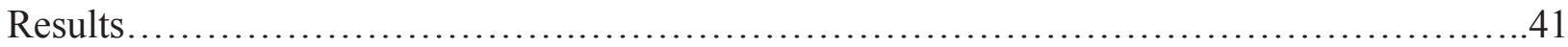

3.1. Part 1: Gifted Children................................................. 41

3.2. Part 2: Comparative Analyses....................................................53

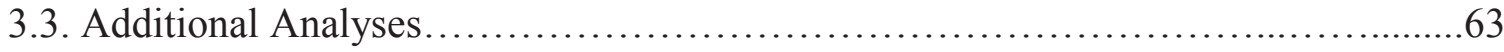

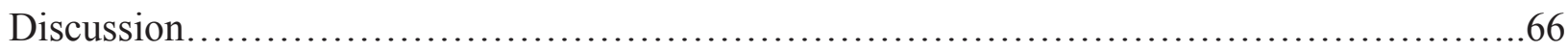

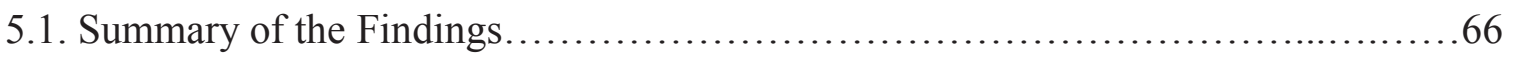

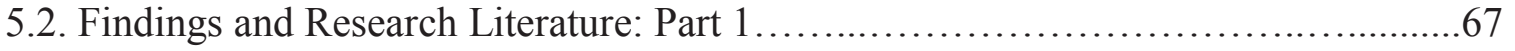

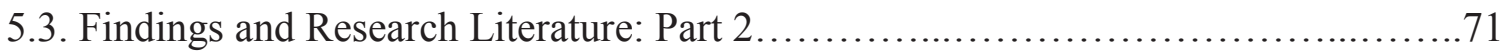

5.4. Alternative Explanations.................................................... 72

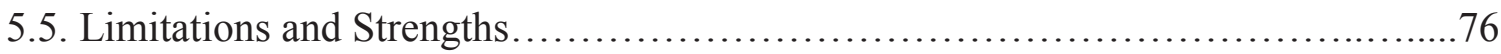

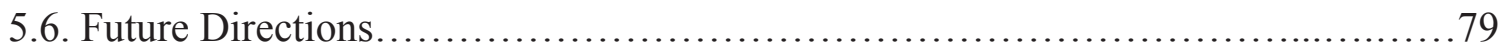




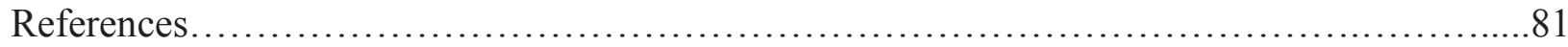

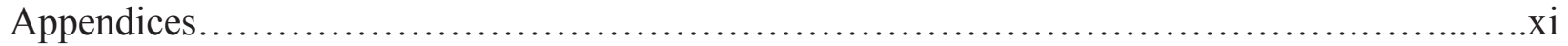

6.1. Appendix A: Parent Consent Form.............................................

6.2. Appendix B: Demographic Questionnaire.....................................xiv

6.3. Appendix C: Teacher Consent Form...............................................

6.4. Appendix D: Sample WISC-IV Item........................................

6.5. Appendix E: PAQ-R ...................................................xii

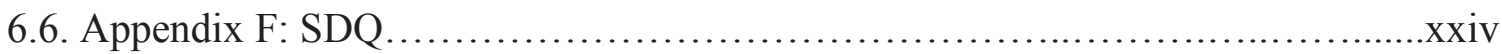

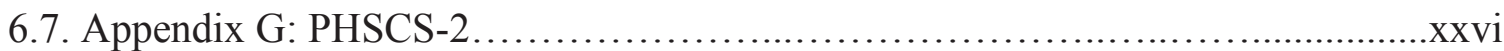




\section{List of Tables}

Table 1: Means (and standard deviations) of demographic characteristics of the samples

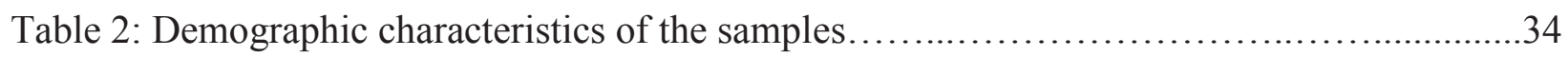

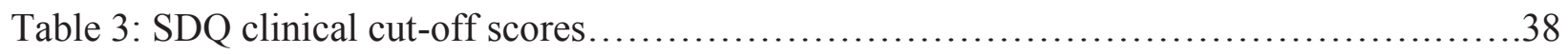

Table 4: Cronbach's alpha coefficients for the PAQ-R subscales completed by mothers

Table 5: Cronbach's alpha coefficients for the PAQ-R subscales completed by fathers

Table 6: Means (and standard deviations) of the PAQ-R scores for mothers and fathers of the gifted sample.

Table 7: Inter-rater means (and standard deviations) of the SDQ scores of the gifted sample identified as having peer social problems....

Table 8: Means (and standard deviations) of the PHSCS-2 scores reported by gifted children identified as having peer social problems

Table 9: Means (and standard deviations) of mothers' SDQ scores for gifted and nongifted children

Table 10: Means (and standard deviations) of fathers' SDQ scores for gifted and nongifted children

Table 11: Means (and standard deviations) of teachers' SDQ scores for gifted and nongifted children

Table 12: Means (and standard deviations) of children's PHSCS-2 scores....

Table 13: Means (and standard deviations) of the PAQ-R scores for mothers and fathers of the nongifted sample

Table 14: Level of agreement for mothers, fathers and teachers on the SDQ. .65 


\section{List of Figures}

Figure 1: Mean scores of the PAQ-R subscales of mothers and fathers of gifted children

Figure 2: Mean scores of the PAQ-R subscales of mothers of gifted children with and without peer social problems.

Figure 3: Mean scores of the PAQ-R subscales of fathers of gifted children with and without peer social problems

Figure 4: Mean scores of the PAQ-R subscales of mothers of gifted and nongifted children

Figure 5: Mean scores of the PAQ-R subscales of fathers of gifted and nongifted children 


\section{List of Abbreviations}

CBCL: Child Behaviour Checklist

CogAT-6: Cognitive Abilities Test Form 6

FSI.: Full scale intelligence quotient

ICC.: Interclass correlation coefficient

IQ: Intelligence quotient

PAAT: Parent as a Teacher Inventory

PAQ-R: Parental Authority Questionnaire-Revised

PHSCS-2: Piers-Harris Self-Concept Scale-Second Edition

SDQ: Strengths and Difficulties Questionnaire

WISC-IV: Wechsler Intelligence Scale for Children-Fourth Edition 


\section{Acknowledgements}

I would fist like to thank my research director, Dr. C. R. Solomon-Scherzer, for her inestimable contribution to this work. Her time, knowledge, expertise and guidance have made this possible. I would also like to thank Dr. Robert Haccoun whom I consulted for statistical help. I would like to extend my gratitude to the parents, teachers, children, and the schools who generously donated their time to participate in this study.

I owe many thanks to my family and friends who have supported and encouraged me throughout this whole process. 


\section{Introduction}

Gifted children present a unique group of the child population due to their advanced aptitudes within arts and sciences (Renzulli, 1978). Despite their facility and ease within these realms, conflicting evidence has emerged over the quality of their psychosocial development. Although most of the research shows that the gifted child is thriving, there are nonetheless continuous reports that some gifted children are having problems. This study will therefore investigate this premise and ascertain whether parenting styles are a factor in gifted child adjustment.

Most research on gifted children has focused on comparing adjustment levels between nongifted children because there is a commonly held stereotype of the maladjusted gifted child (Gallagher, 1990; O’Connor, 2005). This enduring stereotype paints the gifted child as socially awkward, anxious, and arrogant. A theoretical view denotes a similar portrait of gifted children, suggesting that they are more vulnerable to adjustment problems. Within this camp, gifted children's perfectionist personalities, high sensitivity to interpersonal conflict, and tendencies towards being socially isolated are suggested to cause this maladjustment (Pfeiffer \& Stocking, 2000). As a support to this view, studies have shown that gifted children are less well-adjusted than nongifted children (Benony, Van der Elst, Chahraoui, Benony, \& Marnier, 2007; Cornell \& Grossberg, 1987).

Opposing this viewpoint, others propose that it is a result of these advanced abilities, which act as a buffer against depression, low self-esteem, and other adjustment problems that allow gifted children to be just as well-adjusted or more so than nongifted children (Kitano \& Lewis, 2005). In effect, several empirical studies have confirmed that gifted children have equivalent or better adjustment levels than nongifted children (Bracken \& Brown, 2006; Metha \& McWhirter, 1997). 
Given the existence of opposing evidence, the psychosocial adjustment state of gifted children remains unclear. If indeed it is the case that gifted children are prone to adjustment problems, it is imperative to look as to why this might be, since adjustment problems have a negative impact on the general functioning of children in their present as well as in their later years (Kupersmidt \& Coie, 1990).

Psychosocial adjustment, and even cognitive development (Moss, 1990), have been shown to be nurtured through the parent-child relationship (Deater-Deckard, 1998). Although other factors have been found to support and enhance child adjustment, one of the largest contributors is parenting (Maccoby, 1992; 2000). Researchers have largely studied and examined this subject from the perspective of parenting styles, considering the children as a large and undifferentiated population (Baumrind, 1966; 1971). A few studies have examined parenting styles using smaller child samples based on ethnicity (Chao, 2001) and age (Baumrind, 1991).

Only two studies have looked at gifted children and parenting (Cornell \& Grossberg, 1987; Snowden \& Christian, 1999). As it happens, research on the parenting styles of parents of gifted children is lacking. While Snowden and Christian (1999) describe an authoritative parenting style as dominating within families of gifted children, others suggest that a permissive parenting style is commonplace (Cornell \& Grossberg, 1987). To date there is no definite understanding regarding the parenting style of parents of gifted children and less understanding of the effects of parenting style on the gifted child's adjustment level.

The purpose of the present research is therefore to extend the current literature in the field by examining and exploring the relationship between gifted children, and what parenting style is being most commonly used by their parents. This examination will also allow an investigation of whether a particular parenting style is related to positive or negative adjustment in gifted children. 
Furthermore, this research will contribute to the robustness of the current contentions by comparing the adjustment levels of gifted children to nongifted children. Before launching into this investigation, measures of giftedness and child adjustment will be introduced. Next, a review of the literature of adjustment of gifted children and the concept of parenting styles will be presented. Finally, the topic of parenting in relation to the adjustment of gifted children will be discussed.

\section{Measures of Giftedness}

In academic and research settings, giftedness is typically determined by standardized tests such as the Standford-Binet Intelligence Scale (Roid, 2003) and the Wechsler Intelligence Scale for Children (Wechsler, 2003). These standardized tests designate gifted intellectual performance as being two standard deviations above the mean normative score or the 98 percentile. These tests measure cognitive abilities such as vocabulary, working memory, spatial reasoning, and cognitive speed. Vocabulary measures the child's knowledge of words and definition as well as the child's general language development. Working memory measures short-term memory, attention, and concentration. Spatial reasoning measures visual perception and organization of information. Finally, cognitive speed measures mental manipulation of information, concentration, and speed of processing information. For research purposes, standardized tests are a widespread approach to measuring intelligence, however, there are alternative definitions of intelligence that consider other aspects of this construct (Gardner, 1983; Sternberg 1985).

\section{Measures of Child Adjustment}

Child adjustment is measured using several child outcome instruments that quantify behavioural, emotional, and social functioning. An often-used instrument in child adjustment studies 
is the Child Behavior Checklist (CBCL; Achenbach \& Rescorla, 2001) which assesses emotional and behavioural disorders and social skills of children between 4 and 18 years old as reported by their parents. According to this instrument, positive adjustment is construed as the absence of negative behaviours and possible psychological disorders, while negative adjustment is deemed as the presence of said outcomes.

There are instruments that measure the presence of positive traits such as self-esteem and self-concept going along the lines of positive psychology (Seligman \& Csikszentmihalyi, 2000). The Piers-Harris Self-Concept Scale-2 (Piers, Harris, \& Herzberg, 2002) is a self-report questionnaire for children between the ages of 7 and 18. It is completed by (or read to) the child and measures self-perceptions about behaviour, physical appearance, and social belonging. Another instrument that measures the presence/absence of strengths and weaknesses is the Strengths and Difficulties Questionnaire (Goodman, 1997). The advantage of this instrument is that it measures both aspects of adjustment. It measures the presence or absence of emotional, conduct, hyperactivity problems, and the presence of prosocial behaviours such as sharing, helping, and playing with others. With these measures, positive child adjustment can be viewed as a lack of behaviour problems and psychopathology symptoms as well as the presence of positive social behaviours and a positive self-concept. Negative adjustment can be then conceptualized as the contrary of this definition, which is the presence of problems, the absence of prosocial traits, and a low self-concept. The following section will review existing empirical, clinical, and theoretical information on the adjustment levels of gifted children. 


\section{Gifted Child Adjustment}

An important body of literature comparing the adjustment levels of gifted and nongifted children is available. These studies can be grouped into three categories: a) those which conclude gifted children are equally adjusted, b) those which conclude gifted children are better adjusted, and

c) those which conclude that some gifted children may be less well-adjusted than nongifted children. In addition to comparative studies, there are case studies and theoretical literature that examines gifted child adjustment. In this section, these different types of sources of information will be presented.

Comparative studies. Terman (1925-1959) did seminal longitudinal studies on gifted children. His goal was to determine if gifted children had different developmental needs. He followed over 1,500 children between the ages of 8 and 12 years old over a 10-year span. Giftedness was established as an IQ (intelligence quotient) of 140 or higher on the Standford-Binet IQ test (first edition). Terman also compared gifted and nongifted children on height, weight, blood pressure, school grades, and social activities. Gifted children were found to have superior height, weight, and blood pressure measures as well as school grades when compared to nongifted children. It was also found that both gifted and nongifted children engaged in social activities at equivalent rates. With the same sample a decade later, Terman measured marital happiness, family, life, and occupational satisfaction levels on this now adult sample. The gifted adults appeared just as well adjusted as nongifted adults.

More recent studies have continued Terman's work since there were indications from parents and teachers reports that gifted children suffer from emotional and social problems. With this concern in mind, Rost and Czeschlik (1994) wanted to confirm if gifted children were truly less well-adjusted than nongifted children. They compared two groups of 10-year old German children, 
50 gifted children and 50 nongifted children. Giftedness was assessed using the Culture Fair Intelligence Test (Cattell, 1960) and the Cognitive Abilities Test (Thorndike \& Hagen, 1978). Children completed the Anxiety Questionnaire for Children (Wierczerkowski, Nickel, Janowski, Fittkau, \& Rauer, 1974) to measure anxiety levels. Parents completed the Marburg Behaviour Checklist (Ehlers, Ehlers, \& Makus, 1978, as cited in Rost \& Czeschlik), which measures perceived child emotional stability, self-concept, and social behaviour and the Child Characteristics and Behaviours (Ehlers, 1981, as cited in Rost \& Czeschlik), which measures child problem behaviours. Teachers completed the Teacher Behaviour Checklist (Merz, 1983, as cited in Rost \& Czeschlik), which measures child social behaviour. No significant differences were found between the gifted and nongifted children on the measures. The authors proposed that reports on maladjusted gifted children are isolated and that most gifted children do well.

A study done on gifted Spanish children (Lopez \& Sotillo, 2009) aimed to clarify the two opposing theories concerning the gifted child's adjustment. Twenty-five gifted and 25 nongifted children between the ages of 7 and 11 were compared using scores of 130 or above on the Wechsler Intelligence Scale for Children-Revised (Wechsler, 1974). Children completed the Piers-Harris's Children's Self-Concept Scale-Second Edition (Piers, Harris, \& Herzberg, 2002) and the Sociometric Peer Status (Coie \& Dodge, 1983). To evaluate social skills, parents completed the Vineland Adaptive Behaviour Scale (Sparrow, Balla, \& Cicchetti, 1984) to measure perceived social skills of their children. No significant differences were found between the two groups of children. The researchers noted, however, that their study comprised of a small sample of gifted children. As such, they argued that despite mean scores indicating that gifted children as a group do well, their findings do not rule out the presence of a group of gifted children with adjustment problems. This is in contrast to what the study by Rost and Czeschlik (1994) concluded. 
A recent study adopted a different approach to studying the adjustment of gifted children. Perham (2013) compared social skills in gifted and nongifted children in order to understand if gifted children present any difficulties in this area. The researcher argued that public perception and anecdotal reports have maintained that gifted children have problems with social interactions. To clarify this perception using empirical research methods, Perham looked at the social skills of 206 gifted children from kindergarten to grade 8. Gifted children were part of a school district program for the gifted with the entrance criteria being a performance in the 99.5 percentile and above on the Cognitive Abilities Test (Lohman \& Hagen, 2001). Teachers of the gifted children completed the Devereux Student Strengths Assessment (LeBuffe, Shapiro, \& Naglieri, 2009), which measures children's social skills. Gifted children displayed equivalent levels of social skills when their scores were compared to the normative scores of a sample of 2,500 nongifted children of the same age range.

There is another body of literature, done mostly in the United-States, which shows that gifted children demonstrate superior adjustment levels to nongifted children. Lehman and Erdwins (1981) compared two groups of children from grades 3 to 6: 16 gifted children and 24 nongifted children. They conducted this research to verify a theory stating that the social and emotional states of gifted children might not be in line with their advanced cognitive abilities (Jung, 1954). Due to this mismatch, gifted children might encounter problems in social situations. The researchers, therefore, wanted to examine the emotional and social state of young gifted children. Giftedness was determined using the Standford-Binet IQ test with a cut-off score of 130. The California Test of Personality (Thorpe, Clark, \& Tiegs, 1953) and the Children's Social Attitude and Value Scales (Solomon, Kendall, \& Oberlander, 1976) were used measure social attitudes such as cooperation 
and self-esteem among the children. They found that gifted children were significantly more cooperative and had higher self-esteem than the nongifted children.

Ludwig and Cullinan (1984) wanted to study child adjustment from another perspective, therefore they used teacher reports. They compared 54 gifted and 54 nongifted primary school-aged children using the CBCL. Gifted children were identified by scores of 140 or higher on the OtisLennon IQ test (Otis \& Lennon, 1969). Teachers completed the CBCL for both groups. The results showed that the gifted children displayed significantly fewer conduct problems than the nongifted children.

Another investigation of the adjustment of gifted children can be found in the study by Barnett and Fiscella (1985). Contrary to previous studies that have largely considered the adjustment of older gifted children, the researchers wished to investigate the adjustment of gifted young children and adjustment problems in early stages of development. Gifted children enrolled in pre-school were identified by a score of 130 of above on the Stanford-Binet Preschool Intelligence Test (reference not provided). Teachers used the Lieberman Scale (Lieberman, 1977) to observe and measure the social, physical, and cognitive components of play of 15 gifted and 20 nongifted children without knowing which children were identified as gifted. According to this measure, playfulness is composed of five dimensions: physical spontaneity, such as "the child is very physical and active during play," cognitive spontaneity, such as "the child often invents his/her own games to play," social spontaneity, such as "the child often initiates play with others," manifest joy, such as "the child often expresses enjoyment during play," and sense of humor, such as "the child often enjoys joking with other children.” (Barnett and Fiscella, 1985, p. 63). The teachers rated the gifted children as significantly superior on the social and cognitive spontaneity components of play. 
Scholwinski and Reynolds (1985) maintained that despite studies indicating a healthy emotional development in gifted children, the stereotype of the maladjusted gifted child continues to endure. To confirm past studies, they compared the anxiety levels of gifted and nongifted children 6 to 19 years of age. The authors recruited 584 gifted children based on their enrolment in gifted classes, admittance requiring a Standford-Binet or Weschler IQ of 130 or above. The Revised Children's Manifest Anxiety Scale (Reynolds \& Richmond, 1985) was completed by (or read to) the gifted children and the scores were compared to normative scores of this same measure based on 5,000 nongifted children. It was found that gifted children reported significantly less anxiety than nongifted children.

Despite indications that gifted children are doing well and even better than nongifted children, Loeb and Jay (1987) contended that few studies on this subject looked at the self-concept of gifted children. The researchers sought to understand how gifted children viewed themselves. They compared two groups of children. One group consisted of 126 gifted children 9 to 12 years old enrolled in a gifted school program with an entry criteria based on standardized tests (details not provided). The other group consisted of 102 nongifted children in the same age range. All children completed the Nowicki-Strickland Children's Locus of Control Scale (Nowicki \& Strickland, 1973), which measures the perception of personal control that one has on one's life. Self-esteem was measured using the Piers-Harris Children's Self-Concept Scale (Piers \& Harris, 1964). Gifted girls reported significantly greater internal locus of control and positive self-esteem than nongifted girls, while no differences were found between boys.

Subsequent studies continued to examine gifted children and their adjustment using different child outcome measures. Schneider, Clegg, Byrne, Ledingham, and Crombie (1989) wanted to examine two premises. One was whether gifted children's social abilities were as developed as their 
advanced intellectual abilities. As did the Lehman and Erdwins (1981) study, Schneider et al. (1989) proposed that intellectual and social abilities in gifted children might be mismatched and while they excel at academics, they might encounter problems in social interactions. The second premise was to find out if being in specialized gifted classes hindered their adjustment. The researchers explained that while gifted classes might encourage the children's intellectual development, separating them from nongifted children could stigmatize them and thus affect their social adjustment. They measured the academic and social competence of 143 gifted and 143 nongifted children from grades 5 to 10 . Gifted children were registered in a school program for the gifted with an entrance score of 129 or higher on the Henmon-Nelson Test of Mental Ability (Henmon \& Nelson, 1973) or a score above the 97 percentile on the verbal section of the Canadian Cognitive Abilities Test (Thorndike \& Hagen, 1982). The Perceived Competence Scale for Children (Harter, 1982) was administered to measure the child's perceived academic and social competence. The Feelings about School (Bills, 1975) measure was completed by the children to determine their attitude towards school, their classes, peers, teachers, the overall school setting, grades, and extracurricular activities. The results showed that both groups had equivalent perceptions about their school but gifted children viewed themselves as significantly more academically competent. Gifted children presented adequate social adjustment regardless of intellectual ability and whether or not they were in a separate gifted class. Despite these results, the researchers highlighted that parents continue to be concerned about social adjustment problems and peer relations in gifted children. Schneider et al., however, did not specify the source of these parental concerns. Nonetheless, they said there may be a specific group of gifted children that can be experiencing problems and thus who should be examined more closely.

Vallerand, Gagné, Senécal, and Pelletier (1994) assessed the adjustment of gifted children in terms of intrinsic and extrinsic motivation. According to Vallerand et al. (1994), most research on 
motivation has been done with the general child population, and thus they wanted to examine this construct with gifted children. They compared 69 gifted children enrolled in an enriched elementary school program, which had entry criteria based on standardized tests (details not provided), and 66 nongifted children enrolled in the same elementary school. The children completed the Perceived Competence Scale (Harter, 1982) to measure self-competence, and the Intrinsic/Extrinsic Orientation Scale (Harter, 1981) to measure intrinsic motivation. The latter instrument measures the child's preference for challenge, curiosity, and independent mastery in regards to their schoolwork. Gifted children reported themselves to be significantly more self-competent and intrinsically motivated for their schoolwork.

So far, the majority of the comparative studies point to many gifted children doing better than nongifted children. Nevertheless, some comparative studies, as well as one study about parents of gifted children, continue to make mention of a group of gifted children with adjustment problems.

Parker (1996) investigated the psychological adjustment of gifted 12 year olds. The author highlighted that while several studies show that gifted children have a healthy adjustment, parental, and anecdotal reports indicate that gifted children experience problems. Parker used the Brief Symptom Inventory (Derogatis, 1993) to measure the presence of psychopathological symptoms. The inventory was administered to 274 gifted children who performed at the 99.5 percentile or higher on a mathematic aptitude test (details not provided). Their scores were compared to normative scores of the same measure based on a sample of 2,408 nongifted children of the same age. The gifted group reported significantly less somatisation, obsessive-compulsive, paranoid ideation, and psychoticism symptoms as well as significantly less anxiety, depression, interpersonal sensitivity, and hostility. When using the clinical cut-off scores of the Brief Symptom Inventory, 
however, the researcher found 31 of the 274 gifted students with clinical levels of psychopathological symptoms. Parker indicated that the presence of this specific group of gifted students raises questions as to why they would experience adjustment problems.

There are also parent reports of worries about the gifted child. Morawska and Sanders (2009) conducted a qualitative study of 409 parents with gifted children between 2 and 16 years. This study was done on the premise that gifted children have exceptional cognitive skills and thus would present different social, emotional, and educational needs. The researchers argued that these needs are by far handled within the family environment. Hence, understanding the family environment would provide crucial information about the development of gifted children and their specific needs. The children belonged to an independent gifted association. Group as well as telephone interviews were conducted with the parents. They were asked open-ended questions about their parenting and which were the needs of their children. Parents reported that gifted children were anxious and depressed and that they lacked motivation for schoolwork in spite of excellent abilities. The parents also reported difficulties reacting to their gifted children's stubborn and argumentative behaviour.

Jumper (2010) reported that gifted children say they are being bullied more than nongifted children. The researcher explained that bullying is rampant in schools and that gifted children can be more vulnerable to this type of violence because their intellectual abilities set them apart from nongifted children. Consequently, the aim of the study was to examine whether this was the case. The Dan Olweus' Revised Olweus Bully/Victim Questionnaire (Olweus, 1996), which measures types and rates of bullying, was administered to 144 self-identified (details not provided) gifted students and 200 nongifted students in grades 5 to 8 . Gifted students reported being bullied significantly more often than nongifted students. The researcher concluded that this type of abuse 
can have a negative impact on the social and peer interactions of gifted children. Thus, Jumper emphasized the importance of studying gifted children with difficulties in order to develop proper intervention methods to ensure their positive adjustment.

In a meta-analysis of nine studies, Martin, Burns, and Schonlau (2010) sought to identify whether there is group of gifted children vulnerable to problems such as depression and anxiety. They selected studies with child and adolescent samples that were conducted within the last 25 years. The ages of the children ranged from 5 to 18 years old and were mostly American samples. Among the nine studies reviewed, two studies, one conducted in France and the other in Canada, found higher levels of negative adjustment in gifted children compared to nongifted children (Benony, Van der Elst, Chahraoui, Benony, \& Marnier, 2007; Forsyth, 1987). The results of these two studies counter the findings of several other studies. Consequently, this invites further examination of these two studies.

In the first study, Forsyth (1987) compared 42 gifted and 41 nongifted elementary schoolaged children on self-esteem, anxiety, and feelings of security about decision-making using the North York Self Concept Inventory (Rowan, 1985), the State-Trait Anxiety Inventory for Children (Speilberger, 1973), and the Institute of Child Study Security Test (Grapko, 1975). As did Schneider et al. (1989), Forsyth sought to study gifted children in specialized programs to verify if being in a separate program from their nongifted peers was beneficial or harmful to their adjustment. The gifted children in the study were registered at an elementary school that had a gifted program which had entry criteria based on intelligence and creativity measures (details not provided). Gifted girls were found to be significantly more anxious and to have a worse self-concept than the nongifted girls. No significant differences were found between boys. 
In the second study, Benony, Van der Elst, Chahraoui, Benony, and Marnier (2007) suggested a similar premise to that of Lehman and Edwards (1981) and Schneider et al. (1989). Benony et al. (2007) proposed that some gifted children might present social and emotional problems because of an asynchronicity in their cognitive and psychosocial development. To verify this premise, 23, 9 to 13 year old gifted children were compared with 23 same age nongifted students. The gifted children were selected based on scores of 130 or higher on the Wechsler Intelligence Scale for Children-Third Edition (Wechsler, 1991). Parents of both groups completed the CBCL and children completed a self-esteem measure (details not provided). Gifted children reported significantly lower self-esteem in terms of their academic performance. Their parents reported them to have significantly higher depression symptoms on the CBCL.

The remaining seven studies in the Martin, Burns, and Schonlau (2010) meta-analysis can be divided into two broad categories of results; those reporting equivalent adjustment levels (Baker, 1995; Bartell \& Reynolds, 1986; Metha \& McWhirter, 1997; Tong \& Yewchuck, 1996) and those finding higher psychosocial adjustment for gifted children (Bracken \& Brown 2006; Reynolds \& Bradley, 1983; Richards, Encel, \& Shute, 2003). Two studies did report adjustment problems. Martin et al. (2010) concluded that is important to further examine the group of gifted children having problems to understand why they undergo these difficulties. They further added that additional research on this group would encourage the development of programs to address the issues that some gifted children face.

Taking a different direction to studying the adjustment of gifted children, Liratni and Pry (2011) looked at the social intelligence of gifted children. They supported the finding that a group of gifted children experience psychological problems such as anxiety, depression, and oppositional behaviour. Based on the literature on gifted children (Crick \& Dodge, 1994; Hollingworth, 1942), 
the authors proposed that gifted children with adjustment problems may present a lag in their social intelligence. They define social intelligence as the ability to understand others, the ability to understand the intentions of others, and the ability to react adequately to the intentions of others in order to increase one's own inclusion into the social group. In contrast to previous studies on gifted children which compared gifted and nongifted children, the researchers identified a group of gifted children with psychological problems and compared them to gifted children without psychological problems. Giftedness was determined using the Wechsler Intelligence Scale for Children-Fourth Edition (Wechsler, 2003) with an IQ cut-off score of 130 or above. A total of 35 gifted children aged 6 to 13 years old were recruited for the study. Twenty-three gifted children were identified as not having psychological symptoms and 12 gifted children were identified as having psychological symptoms, such as depressive, anxious, and oppositional disorder symptoms using the International Classification of Diseases-Tenth Revision (World Health Organization, 2010). Social intelligence was measured using three of the four scales of the Vineland Adaptive Behaviour Scales (Sparrow, Balla, \& Cicchetti, 1984): communication, socialisation, and daily living skills. Communication measures the child's ability to understand and transmit verbal and written information. Socialisation measures the child's inclusion in groups of friends, sports, and leisure. Daily living skills measure the child's ability to take care of personal hygiene, dress oneself, perform domestic tasks, use money, and tell time. Gifted children identified with psychological problems scored significantly lower on all three aspects of social intelligence. The authors concluded that gifted children with problems have shortcomings in their social abilities. They pointed out, however, that their study did not look at the family dynamics of gifted children. They argued that this could be an important factor that may help explain why some gifted children experience psychological and social problems. 
Case studies. Other sources of information supported the idea of a gifted group of children with adjustment problems. Based on a review of 30 years of research on gifted children and adolescents done by Niehart (1999), Reis and Renzulli (2004) concluded that gifted youth as a whole present normal levels of adjustment but some still encounter problems such as a tendency to underachieve and display perfectionist traits. Reis and Renzulli theorized that this could occur due to an unsupportive environment. Hence, they studied two gifted children from pre-school school to high school in order to find out if these phenomena were present (methodology not provided). From the information gathered from these two cases, Reis and Renzulli reported that there is lack of a supportive environment, such as unsupportive parents, few friends, and few academic challenges for gifted children. Reis and Renzulli stated that gifted children are predisposed to social difficulties with their peers and family because of a combination of their advanced abilities and an unsupportive environment. They explained that gifted children have advanced cognitive skills, such as curiosity and critical thinking. They suggested that these skills can be off-putting to their peers and family. If the children are also exposed to an unsupportive environment, the chances of maladjustment increase. Like Martin et al. (2010), Reis and Renzulli support the proposition that a group of gifted children are undergoing difficulties and the importance of studying this group.

Sankar-DeLeeuw (2004) observed the interactions of four gifted children at the kindergarten level using a case study method. The researcher sought to study the developmental and educational needs of gifted children just entering school since very little is known about younger gifted children. The children were recruited from various schools within the same school board and had to achieve an IQ score of 130 or above on the Standford-Binet Intelligence Scale-Fourth Edition (Thorndike, Hagen, \& Sattler, 1986) to take part in the study. The researcher observed the children at home, at school and in extracurricular settings such as sporting games and music classes. She also conducted 
semi-structured interviews with the parents, teachers, and the children. The researcher found that the gifted children had a preference for solitary activities, such as reading and writing, had high motivation for tasks, such as practicing mathematics, sports, and computer skills, and a need to keep busy with activities, such as completing workbooks. The gifted children also displayed perfectionistic behaviours, crying when unable to answer a question from a teacher or repeatedly starting over a drawing. The researcher also noted that gifted children seemed to prefer the company of older children and adults. Sanker-DeLeeuw proposed that because of differing cognitive levels, perhaps gifted and nongifted children fail to understand each other and bond, and thus older children or adults might better match the interest of gifted children.

Theoretical sources. In addition to clinical evidence, some researchers advance theories to explain why gifted children have problems. Based on five studies on gifted adolescents done in the United States, Nugent (2000) reported that some gifted students (up to $87.5 \%$ in one study on gifted middle-school students) can have perfectionist tendencies. The author theorized that these perfectionist traits can impact the gifted child's emotional well-being and negatively affect relationships with family and friends. Behaviours such as delaying completion of tasks, repeatedly starting work over, unwillingness to share work, impatience with their own or others mistakes, and overly emotional reactions to errors can lead to alienation from working and playing with other children.

Pfeiffer and Stocking (2000) argued that since gifted children perform exceedingly well academically, psychosocial problems might go unnoticed. On the basis of this argument, Pfeiffer and Stocking laid out several risk factors relevant to gifted children. They suggested that gifted children's advanced development can isolate them from their peers and produce unrealistic expectations in teachers and parents, thereby triggering anxious and depressive moods and 
externalizing behaviours. Pfeiffer and Stocking also theorized that high excitability is another characteristic of the gifted child, a topic previously addressed by Piechowski (1999). The gifted child can display great amounts of physical, creative, and intellectual energy which can be viewed as problematic behaviour in school or at home, especially if the school curriculum does not provide challenging work and if the parents do not provide intellectual stimulation to the child. Teachers can deem behaviours such as fidgeting in class, being distracted or bored as negative and disruptive behaviour. A review of 11 dissertation studies on this trait (Chang \& Kuo, 2013) supports this theory. Chang and Kuo (2013) examined the overexcitability ratings made by teachers of gifted $3^{\text {rd }}$ to 12 th grade students. They concluded that gifted students demonstrated significantly more intellectual, psychomotor, and emotional overexcitability than nongifted students. They found that intellectual overexcitability (e.g., thinking about and figuring out problems) was associated with positive adjustment, while psychomotor (e.g., not sitting still) and emotional overexcitability (e.g., somatic complaints) were associated with negative adjustment. Therefore, emotional and psychomotor overexcitability behaviours may make gifted children less accepted in peer groups. Given that most of the studies show that gifted children do well, Pfeiffer and Stocking emphasized that it is especially important to identify this group of gifted children and address their needs because ignoring this can lead to more severe problems later on and have a negative effect on their academic and professional success not to mention their general well-being.

As shown in the above section, empirical studies, case studies, and theoretical sources indicate that some gifted children experience adjustment problems. Certain researchers have suggested that adjustment problems are linked to family. Reis and McCoach (2000) reviewed over 30 studies on the characteristics gifted adolescents who underachieve at school. They concluded that gifted students who underachieved tended to have low self-concept and to be anxious, withdrawn, 
and depressed. Based on parenting literature showing that adjustment problems are related to the family environment, Reis and McCoach proposed that adjustment problems in gifted youth can also be related to the family milieu amongst other factors. They suggested that certain parenting practices such as being overly strict or lenient may be linked to academic underachievement of gifted students. Also, in his study, Parker (1996) concluded that some gifted children have adjustment problems and that family patterns might be one of several contributors to maladjustment.

Parenting behaviours, in particular, are considered an important contributor to child development, because as far as environment influences are concerned, they are the most crucial aspects that influence a child's adjustment, especially during early childhood (Deater-Deckard, 2000; Kiff, Lengua, \& Zalewski, 2011; Maccoby, 1992; 2000; Morris, Silk, Steinberg, Sessa, Avenevoli, \& Essex, 2004). Studies by Morris et al. (2004) and Deater-Deckard (2000) hold that child adjustment is a product of the interplay between genetic and environmental influences. Child temperament but also parenting behaviours, such as displays of affection and control, have an impact on child adjustment. Maccoby (1992) argued that the socialization and adjustment of the young child are heavily shaped by the parent-child relationship. Though genetics do play an integral role, parenting is shown to be the most important among the environmental influences, thus its role should not be diminished (Kiff et al. 2011; Maccoby, 2000).

One of the most researched parent influences is that of parenting styles. There is a large body of research that shows a strong association between parenting styles and children's adjustment (Kaufmann, Gesten, Lucia, Salcedo, Rendina-Gobioff, \& Gadd, 2000; Michalchio \& Solomon, 2002; Querido, Warner, \& Eyberg, 2002). In the following section, the concept of parenting styles will be presented as well as a brief summary of the research of the effects of parenting on gifted children. 


\section{Baumrind's Parenting Styles}

The parenting style construct was first presented by psychologist Diana Baumrind (1966). She conducted research by observing children's behaviour in preschool and the behaviour of their mothers. Based on these observations, she described three types of parenting styles: authoritarian, authoritative, and permissive.

Baumrind (1967; 1971) observed children's interpersonal and social behaviour in nursery school and home settings. In 1971, Baumrind used the Preschool Behaviour Questionnaire (Baumrind, 1968b) to rate a sample of 150 children in regard to their behaviour with their peers. This questionnaire measures child characteristics such as whether the child understands other children's needs, whether the child is nurturing or sympathetic towards other children, and whether the child leads play activities and is obedient to adults. Parental behaviour with the children was observed during two home visits. Parental behaviour was rated on 75 behaviour items, such as "sets regular tasks," "has many rules and regulations," and "does not share decision-making power with child." (Baumrind, 1971, pp.15-17). In addition, in a structured interview, the parents answered questions about their disciplinary methods, the rules in the household, and how they responded to child requests and parent-child conflicts.

According to the results, the parents were ascribed one of three main styles of parenting behaviour: authoritarian, authoritative, and permissive. Parents who were rated as controlling, uncommunicative, cold, and rejecting had children who were rated as withdrawn, unhappy, and distrustful. This group of parenting behaviours was designated authoritarian. Parents who were demanding and controlling but were also warm and communicative had children who displayed self-reliant, self-controlled, and exploratory behaviours at preschool. This parenting style was designated as authoritative. Finally, parents who were undemanding, warm, and communicative had 
children who were rated as dependent and fearful. These types of parenting behaviours were termed permissive.

Baumrind categorized these three parenting styles on four dimensions of parent behaviour. The first dimension is the level of control the parent exerts on their child; how much the parent regulates and supervises their child's behaviour. At one end of the continuum, there are parents who are very lenient, making few demands on their children, allowing them to take major and minor decisions regardless of the age. On the other end, there are parents who are highly demanding and controlling, essentially dictating the lives of their children. The second dimension is the level of warmth. This dimension describes the level of physical, verbal and nonverbal affection the parent shows to their child, and how much time the parent spends with their child. A parent with low warmth is unaffectionate and spends little time playing and talking with their child, whereas a parent with high affection plays, talks, hugs, and praises their child. The third dimension is level of communication or the extent to which the parent shares information with their child. A parent low on the communication dimension shares little about his or her feelings and thoughts with their child. At the other end of the continuum, the parent with high communication talks about many topics, personal feelings, and thoughts and takes an interest in their child's experiences at school and with friends. Finally, the fourth dimension is level of expectations. This dimension refers to the parent's expectations of what is appropriate child behaviour at each age. Parents with a low level of expectations dot not place specific developmental demands on their child. Parents with high expectations make developmentally appropriate demands on their child.

The authoritarian parent has a set of strict rules and standards for their child. This parent expects their child to conform to expectations and demands without question. The authoritarian parent applies the rules without explaining them. These parents expect obedience and use physical 
or verbal punishment to enforce it. That is they use domineering and arbitrary control based on the subordinate status of the child to the parent (Baumrind, 2012). The child's behaviour is closely monitored. Family life is highly ordered and structured according to the parent's standards. These standards are based on social or religious sources (Baumrind, 1968a). This parenting style is defined dimensionally as high on control and expectations, and low on warmth and communication.

The authoritative parent also applies rules and expects their child to obey them. This parent, however, will listen to objections or requests from their child and is open to comprise on rules and expectations. The authoritative parent will consider the point of view of the child and may modify decisions accordingly. This parent is willing to use reason by discussing parental decisions with their child and by explaining the reasons behind the rules. This type of control is firm yet direct and consistent rather than arbitrary and domineering like the authoritarian parenting style (Baumrind, 2012). The authoritative parenting style allows the child the opportunity to question situations and rules and to express objections. This parent has a set of expectations based on set standards for future conduct rather than based on societal or religious standards of behaviour (Baumrind, 1968a). The authoritative parent is communicative and expresses affection to their child. This parenting style is situated on the high control, high warmth, high communication, and high expectations dimensions.

The permissive parent has few rules. They allow their child to make his or her own choices, even if these choices are inappropriate. The permissive parent consults with their child about family decisions and rules even when it is not appropriate to do so. They avoid verbal or physical punishment. The permissive parent generally lets their child do as he or she pleases. Parental expectations are based on the child's desires (Baumrind, 1968a). This parenting style falls low on the control and expectations dimensions and high on the warmth and communication dimensions. 
As series of studies with various groups of subjects has shown that authoritative parenting is associated with healthy adjustment of the child, such as a lack of learning difficulties, negative mood, and externalizing behaviours in children (Kaufmann, Gesten, Lucia, Salcedo, RendinaGobioff, \& Gadd, 2000) and adolescents (Baumrind, Larzelere, \& Owens, 2010; Dwairy, Achoui, Abouserie, \& Farah, 2006; Slicker, 1998). Authoritarian parenting has been associated with feelings of frustration, insecurity, and confusion (Chen, Dong, \& Zhou, 1997), poor social competence (Dekovic \& Janssens, 1992), and with a greater risk of developing conduct problems (Thompson, Hollis, \& Richards, 2003). Permissive parenting has been linked to social withdrawal, anxiety, and depression in children (Williams, Degnan, Perez-Edgar, \& Henderson, 2009).

Research shows that specific parenting styles have either a negative or positive impact on child adjustment. As with nongifted children, it is possible that an authoritative parenting style would have a positive effect on the adjustment of gifted children, whereas authoritarian and permissive parenting styles would have negative impacts. Gifted children, however, are cognitively and developmentally different. It is conceivable then that different parenting styles might be better suited for them. In order to gain a better understanding of this topic, studies that have examined aspects of parenting and the adjustment of gifted children will be presented in the next section.

\section{Parenting and Gifted Child Adjustment}

To the best of the researcher's knowledge, studies of parenting of gifted children are limited. One study examined the family characteristics and adjustment of 83 families of gifted children 7 to 11 years of age (Cornell \& Grossberg, 1987). The children were enrolled in a school program for the gifted, which had an entrance criteria based on the Wechsler and Standford-Binet tests (references not provided). The researchers' goal was to identify the family characteristics of gifted 
children and to see if these have an effect on gifted children's adjustment. They explained that research has shown certain parenting behaviours are beneficial to the cognitive development of children. They wanted to expand this research to see what types of family characteristics are associated with gifted children's psychosocial development. In addition, based on previous studies, such as those of Leaverton and Herzog (1979) and Whitmore (1980), the researchers emphasized the presence of a group of gifted children with adjustment problems. To verify if there is such a group, they also compared the adjustment levels of gifted and nongifted children on various measures. Children completed the Coppersmith Self-Esteem Inventory (Coopersmith, 1981) and the Revised Children's Manifest Anxiety Scale (Reynolds \& Paget, 1983). Parents completed the Family Environment Scale (Moos \& Moos, 1981) and the Revised Personality Inventory for Children (Lachar, 1982). Teachers completed the Behavioural Academic Self-Esteem Scale (Coopersmith \& Gilbert, 1982). The scores of the gifted sample on these measures were compared to the normative scores of large samples of nongifted children of the same age range.

In the first part of their study, Cornell and Grossberg (1987) looked at the gifted children's family characteristics for relationships between them and gifted child adjustment. They measured 10 family characteristics based on Moos and Moos's (1981) concepts of cohesion, expressiveness, conflict, independence, achievement orientation, intellectual-cultural orientation, active-recreational orientation, moral-religious emphasis, organization, and control. They described cohesion as the extent of help and support family members provide for each other. Expressiveness was described as the extent to which family members encourage each other to discuss their feelings. The quality of the expressiveness characteristic and whether it included both positive and negative expression of feelings was not specified. Conflict was characterized as the amount of openly expressed anger, aggression, and conflict among family members. Independence was described as the extent to which 
family members are assertive, self-sufficient, and make their own decisions. Achievement orientation was defined the extent to which activities (e.g., school and work) are placed into a competitive framework. Intellectual-cultural orientation was designated as the degree of interest the family devotes to political, social, intellectual, and cultural activities. Active-recreational orientation was defined as the extent of family participation in social and recreational activities, while moralreligious emphasis was characterized as the degree of emphasis the family places on ethical and religious issues and values. Organization denoted the degree of importance of clear organization and structure in planning family activities and responsibilities. Lastly, control was described as extent to which set rules and procedures are used in family life. The researchers compared the mean scores on these 10 family characteristics to the mean scores of 1,125 families with nongifted children. Parents with gifted children reported significantly higher cohesion, expressiveness, intellectual-cultural orientation, and active-recreational orientation scores and significantly lower achievement orientation and control scores. The scores on the other family characteristics were not significantly different. From these results, the researchers concluded that families of gifted children value cohesion, expressiveness, recreational, and intellectual pursuits, but not in a competitive context. Also, these families scored low on the control characteristic, which, according to the researchers, reveal a lack of emphasis on setting rules and procedures in the family. The researchers did not base the family characteristics on Baumrind's work, and thus they did not state whether they refer to a certain parenting style. The characteristics, however, can be paralleled to the dimensions described in the previous section. The families in this study reported high cohesion (i.e., warmth), expressiveness (i.e., communication), and low control, characteristics reflective of a permissive parenting style. Cohesion and expressiveness characteristics were significantly correlated with fewer conduct problems, less anxiety, and higher self-esteem and school achievement in the gifted 
children. Lower family conflict was significantly associated with lower overall negative adjustment scores. Active-recreational orientation and moral-religious emphasis scores were significantly and positively correlated with somatic symptoms in gifted children. The independence, achievement orientation, intellectual-cultural orientation, organization, and control characteristics were not found to be significantly correlated with any child outcome.

In a second part of the same study, the adjustment levels between gifted and nongifted children were compared. Parents reported that gifted children were significantly less socially competent and had less emotional self-control as well more somatic symptoms than nongifted children. Gifted children, however, reported significantly higher self-esteem and significantly lower anxiety than nongifted children. Teachers also reported significantly higher self-esteem for the gifted sample.

Aside from the comparative results, Cornell and Grossberg (1987) detected different perceptions of adjustment levels of the gifted children from the various participants. The parents disagreed with the children and teachers on the different adjustment measures. Teachers and children, however, agreed on the self-esteem measure. Parents reported their gifted child as having less social competence and emotional self-control, and more somatic symptoms. Gifted children, however, reported high self-esteem and less anxiety. In addition, teachers reported high self-esteem in gifted children. These findings show that the perception of adjustment varies between the parents and the children as well as the teachers.

Snowden and Christian (1999) studied the parenting behaviour of parents of gifted children between three and five years old. They suggested that parenting these children might be different from parenting nongifted children. They highlighted the importance of understanding parent-gifted child interaction in order to foster the gifted child's development. The researchers administered a 
self-report measure, the Parent as a Teacher Inventory (PAAT; Storm, 1984), to 46 parents of gifted children who were enrolled in a pre-school gifted program. The instrument measures five areas of parenting: creativity, frustration, control, play, and teaching-learning. Creativity refers to the extent to which parents encourage their child to make independent decisions, frustration refers to the extent to which parents make appropriate demands on their child, control refers to how much parents share the decision-making with their child, play refers to the extent parents encourage playing and playful behaviours in their child, and teaching-learning refers to the parents' belief in their ability to act as teachers to their child. The researchers also conducted interviews with the parents and observed them in interaction with their children.

Based on cut-off scores of the PAAT instrument, parents reported mean scores in the high range for all five areas of parenting. The highest mean score was for the teaching-learning, followed by the play, frustration, creativity, and control areas. Also, from the interviews and observations, the researchers found that parents encouraged their children to be creative and make independent judgements. They allowed them to openly express feelings of frustration and they played with them. The parents set expectations according to their child's needs and age, and let their child make certain decisions relating to the home and family life. Again the measures used were not based on Baumrind's system, but the authors pointed to Baumrind's authoritative parenting style as defining the family traits of gifted children.

Since studies on the parenting of gifted younger children are scarce, two studies on parenting of gifted adolescents will be presented in order to provide additional information on this topic. One study (Dwairy, 2004) searching for the effects of family environment on gifted students was conducted on gifted 14 year-olds Arab adolescents. The parenting styles of parents of 118 gifted adolescents enrolled in a gifted school program were compared to those of 115 nongifted 
adolescents. Gifted adolescents were chosen based on scores of 140 or above on the Wechsler Intelligence Scale for Children-Revised (Wechsler, 1974). To ascertain parenting styles, the adolescents completed a version of the Parental Authority Questionnaire (Burri, 1991), which assesses parenting styles from the adolescent's point of view.

All the adolescents rated their parents as being predominantly authoritative. Gifted adolescents, however, rated their parents as significantly more authoritative and more permissive than did the nongifted adolescents. Nongifted adolescents rated their parents as significantly more authoritarian. Higher scores on the authoritative parenting style were related to fewer psychological symptoms for both groups of adolescents. Higher scores on the authoritarian parenting style were related to more psychological problems in gifted adolescents only. These results are in line with the conclusions of the research on parenting styles in general. It would be important to find out if these relationships are present in younger gifted children.

Dwairy (2004) also compared the adjustment levels of the two groups. Adolescents completed the Lipsitt's Self-Concept Scale for Children (Lipsitt, 1958) the Rosenberg Self-Esteem Scale (Rosenberg, 1965) and the Psychological State Scale (Hamuda \& Imam, 1996). In comparison to the nongifted group, gifted adolescents reported significantly higher self-esteem. Gifted adolescents also reported significantly less depression, fewer anxiety symptoms, and fewer conduct problems.

Rudasill, Adelson, Callahan, Houlihan and Keizer (2013) looked at gifted students between 9 and 17 years old and their perceptions of their parents' parenting style in relation to their cognitive abilities. As did Cornell and Grossberg (1987), the researchers proposed that parenting behaviours have an effect on the cognitive performance of children in general and wanted to see if this was so with gifted students. Participants were 332 students attending a summer program for gifted students. 
They completed the Parental Authority Questionnaire (Buri, 1991) and the Cognitive Abilities Test Form 6 (CogAT-6; DiPerna, 2005). They found higher authoritative scores were related to higher CogAT-6 scores. Higher authoritarian and permissive scores were related to lower CogAT-6 scores. This study supports the literature on parenting, in that authoritative parenting seems to be connected to positive child and adolescent outcomes, while authoritarian and permissive parenting are related to negative outcomes.

In summary, one study on gifted children showed that parents of gifted children report using an authoritative parenting style with gifted children aged 3 to 5 years old (Snowden \& Christian, 1999). Another study found parents of gifted children aged 7 to 11 years old using little control but a lot of communication and support, which appears to suggest Baumrind's permissive parenting style (Cornell \& Grossberg, 1987). Although the gifted children were not in the same age range in the two studies, they nonetheless present different results. It is therefore apparent that more studies are needed on this topic.

\section{Current Study}

As outlined in the literature review above, empirical and clinical evidence shows that some gifted children have adjustment problems. Parenting styles may be one of the explanations of why this group has problems. To date, no study on the parenting of younger gifted children has been done using Baumrind's models. It is evident that further research on parenting of gifted children is necessary. This study, therefore, sought to answer six questions. The first question was what parenting styles do parents of gifted children use. The second question asked whether parents of gifted children with adjustment problems use a different parenting style from that of parents of other gifted children. The third question asked whether a particular parenting style is linked to the 
adjustment of gifted children. This study also sought to confirm previous comparative studies by asking whether the adjustment levels of gifted children and the parenting styles of their parents differed from those of nongifted children. The final question asked was whether the associations between parenting styles and child adjustment differed between gifted and nongifted children. The answers to these questions would provide important information on the functioning of gifted children and their parents.

\section{Research Objectives}

With the above questions in mind, the current study had two parts. Part 1 examined parenting styles and the adjustment of gifted children. Part 2 compared the adjustment of gifted and nongifted children and parenting styles. The following objectives were formulated for this study: Part 1:

(1) To identify the parenting styles of parents of gifted children.

(2) To identify the parenting styles of parents of positively and negatively adjusted gifted children.

(3) To determine whether parenting styles are correlated with positive and negative adjustment in gifted children.

Part 2:

(4) To confirm whether gifted children are better or less well-adjusted than nongifted children.

(5) To compare the parenting styles of parents of gifted and nongifted children.

(6) To compare the associations between parenting styles and adjustment in gifted and nongifted children. 


\section{Method}

\section{Participants}

A total of 100 mother child dyads took part in this study. Sixty-four fathers and 67 teachers also participated. Participants were recruited through Montreal independent elementary schools, parent associations, and local media (advertisements). Interested parents contacted the researcher by telephone or by email and then had a fifteen minute telephone interview in order to determine whether they met the criteria for the study. The inclusion criteria included the age of the child, between 7 and 11 years of age, that they were English-speaking and that parents saw their child as gifted and reported indices such as obtaining very high marks or being bored at school. If the criteria were met, a home visit was scheduled.

The home visit lasted approximately two hours. During this visit, parents completed a consent form (see Appendix A) and a demographic questionnaire (Appendix B). In addition, they completed two questionnaires, one about their parenting styles and one about their child's psychosocial adjustment. While the parents completed the questionnaires, the researcher administered an IQ test and a self-concept questionnaire to the child. Children who achieved an IQ of 130 or above were placed into the gifted sample. Children who achieved and IQ of 129 or below were placed into the nongifted sample. Teachers who knew the child best were asked to complete a short questionnaire about the child's psychosocial adjustment, along with a consent form (see Appendix C). The teachers returned the completed consent form and questionnaire to the researcher using a preaddressed stamped envelope.

Gifted sample. Forty-eight children were identified as gifted (23 boys and 25 girls). Their mean IQ was $140.96(S D=7.84)$. Their mean age was $8.40(S D=1.28)$. Forty-eight mothers, 33 fathers, and 36 teachers completed the questionnaires. The mean age of the mothers was 41.52 
$(S D=5.36)$ and the mean age of the fathers was $42.66(S D=5.36)$. The mean number of children in the household was $2.23(S D=1.10)$. Forty-three mothers had completed a university degree. Four mothers had completed college studies and one mother had completed high school. Of the 33 fathers, 28 fathers had completed university, three fathers had completed college, one father had completed high school, and one father had not completed high school. Forty mothers were married and lived with the child's father, two mothers lived with the child's father but were not married, two mothers were separated from the child's father, one mother was divorced, one mother was widowed, and two mothers had never been married and did not live with the child's father.

Nongifted sample. Fifty-two children were identified as nongifted (31 boys and 21 girls). Their mean IQ was $117.52(S D=7.57)$. Their mean age was $8.52(S D=1.46)$. Fifty-two mothers, 31 fathers, and 31 teachers took part in the study. The mean age of the mothers was 40.23 ( $S D=$ 7.86) and the mean age of the fathers was $45.22(S D=7.51)$. The mean number of children in the household was $2.29(S D=0.78)$. Forty-four mothers had completed a university degree. Six mothers had completed college, one mother had completed high school, and one mother had not completed high school. Twenty-three of the 31 fathers had completed university. One father had completed college, six fathers had completed high school, and one father had not completed high school. Forty-two mothers were married and lived with the child's father, one mother lived with the child's father but was not married, one mother was separated from the child's father, four mothers were divorced, two mothers were widowed, and two mothers had never been married and did not live with the child's father. The IQ scores of the two child samples were significantly different, $t(98)$ $=15.21, p=.000$. No other differences were found to be significant. See Tables 1 and 2 (pp. 34-35) for sample characteristics of both groups. 
Table 1

Means (and standard deviations) of demographic characteristics of the samples

\begin{tabular}{lccc}
\hline & Gifted Sample & Nongifted Sample & Statistic \\
Characteristic & $(n=48)$ & $(n=52)$ & \\
\cline { 2 - 3 } & & Mean \\
\hline
\end{tabular}

Demographic

$\begin{array}{lccc}\begin{array}{l}\text { Age Child (years) } \\ \text { (Standard deviation) }\end{array} & 8.40 & 8.52 & -0.45 \mathrm{~ns} \\ & (1.28) & (1.46) & \\ \text { Child IQ } & 140.96 & 117.52 & 15.21^{* * *} \\ \text { (Standard deviation) } & (7.84) & (7.57) & \\ & & & 0.95 \mathrm{~ns} \\ \text { Age Mothers (years) } & 41.52 & 40.23 & \\ \text { (Standard deviation) } & (5.36) & (7.86) & -1.53 \mathrm{~ns} \\ & & & \\ \text { Age Fathers (Years) } & 42.66 & 45.22 & -0.31 \mathrm{~ns} \\ \text { (Standard deviation) } & (5.36) & (7.51) & \\ & & & \end{array}$

Note. ns = not significant.

${ }^{*} p \leq .05 .{ }^{* *} p \leq .01 .{ }^{* * *} p \leq .001$. 
Table 2

Demographic characteristics of the samples

\begin{tabular}{ccc}
\hline Gifted Sample & Nongifted Sample & Statistic \\
$\chi^{2}$ & $(n=52)$ & \\
\hline & \\
\hline
\end{tabular}

Count

Child Gender:

$\begin{array}{llll}\text { Male } & 23 & 31 & 1.38 \mathrm{~ns} \\ \text { Female } & 25 & 21 & 1.38 \mathrm{~ns}\end{array}$

Count

Education Mother: University

Education Father:

University

28

23

$5.57 \mathrm{~ns}$

Civil Status:

Married

40

42

$5.36 \mathrm{~ns}$

Note. $\mathrm{ns}=$ not significant. 


\section{Measures}

Giftedness was evaluated using the Wechsler Intelligence Scale for Children-Fourth Edition (WISC-IV; Wechsler, 2003). Parenting style was measured using the Parental Authority Questionnaire Revised (PAQ-R; Reitman, Rhode, Hupp, \& Altobello, 2002). Child psychosocial adjustment was measured using the Strengths and Difficulties Questionnaire (SDQ; Goodman, 1997), completed by the parents and teachers. To determine psychosocial adjustment from the child's perspective, children completed or responded to the Piers-Harris Self-Concept Scale-Second Edition (PHSCS-2; Piers, Harris, \& Herzberg, 2002).

Wechsler Intelligence Scale for Children-Fourth Edition (WISC-IV). The WISC-IV is an instrument administered individually that measures cognitive abilities in children between 6 and 16 years old (Wechsler, 2003). The WISC-IV is composed of 10 subtests (see Appendix D for a sample WISC-IV item). A Full Scale Index (FSI) is derived which displays general cognitive ability. A FSI score of 130 or above was used in this study to indicate giftedness, based on the categories outlined in the WISC-IV manual (Wechsler, 2003, p. 75). The WISC-IV takes approximately 65-80 minutes to administer.

WISC-IV reliability. The average reliability coefficients between the WISC-IV subtests are good, ranging from .78 to .88 (Wechsler, 2003). Internal consistency has been shown with different child populations, including gifted children, ranging between .86 and .94 (Hagmann-von Arx, Meyer, \& Grob, 2008). The WISC-IV has also adequate test-retest reliability across time for all age groups. The stability coefficient for the subtests ranges between .73 and .91 (Wechsler, 2003).

WISC-IV validity. Convergent and discriminate validities of the WISC-IV are evidenced through intercorrelation scores. Subtests within the Verbal Comprehension Index correlate highly 
with each other (i.e., $r=.70$ for Vocabulary and Similarities subtests), indicating good convergent validity. Subtests from separate indexes show low correlations (i.e., $r=.29$ for Comprehension and Block Design subtests), demonstrating divergent validity (Wechsler, 2003). Good concurrent validity is also evident with a similar instrument, the Wechsler Individual Achievement Test, with an $r=.80$ (Wechsler, 2001).

Parental Authority Questionnaire-Revised (PAQ-R). The PAQ-R is a self-report questionnaire to be completed by parents of children between 3 and 11 years-old (Reitman, Rhode, Hupp, \& Altobello, 2002). The PAQ-R is composed of 30 items, divided into three subscales of 10 items each representing authoritarian, authoritative, and permissive parenting styles (see Appendix E). Authoritarian are items 2, 3, 7, 9, 12, 16, 18, 25, 26, 29, authoritative are items 4, 5, 8, 11, 15, $20,22,23,27,30$, and permissive are items 1, 6, 10, 13, 14, 17, 19, 21, 24, 28. Parents rate themselves on each item on a 5-point Likert-type scale that ranges from 1 (strongly disagree) to 5 (strongly agree). Each parent obtains a score ranging from 10 to 50 for each parenting style subscale. A high score on a particular subscale indicates that the parent uses more of that parenting style.

Parental Authority Questionnaire-Revised reliability. The internal consistency of the PAQ$\mathrm{R}$ subscales has been shown to be satisfactory. The items within each of the three subscales measure the same concept, the authoritarian, authoritative or permissive parenting styles. Coefficient alphas for the authoritarian, authoritative, and permissive scales are reported to vary from .72 to .77 (Reitman, Rhode, Hupp, \& Altobello, 2002). Good test-retest reliability is shown for the PAQ-R; 0.87 for authoritarian, 0.61 for authoritative, and .67 for permissive subscales (Reitman et al., 2002).

Parental Authority Questionnaire-Revised validity. Adequate convergent validity has been shown with significant correlations, $r$ of .25 to .34 , with scales of conceptually similar 
questionnaires such as the Parent-Child Relationship Inventory (Reitman, Rhode, Hupp, \& Altobello, 2002). As for divergent validity, the three PAQ-R subscales are significantly negatively correlated. The authoritarian subscale is negatively related to the permissive scale, $r=-.38$, and to the authoritative scale, $r=-.48$. The permissive scale is not significantly related to the authoritative scale, $r=.07$ (Buri, 1989).

Strengths and Difficulties Questionnaire (SDQ). The SDQ is a 25-item behavioural screening questionnaire intended for parents and teachers to evaluate children between 3 and 16 years old (see Appendix F; Goodman, 1997). The 25 items are divided into five subscales: emotional problems: items $3,8,13,16,24$; conduct problems: items 5, 7, 12, 18, 22; hyperactivity: items $2,10,15,21$, 25; peer social problems: items $6,11,14,19,23$; and prosocial behaviours: items 1, 4, 9, 17, 20. The first four subscales measure "weaknesses" (i.e., adjustment problems). A total score is derived by adding the four weakness subscales scores, which indicates overall negative or positive adjustment. A higher score indicates negative adjustment and a lower score indicates positive adjustment. The prosocial behaviours subscale measures "strengths" but it is not calculated in the total score. It can be used as a second indicator of positive or negative adjustment. A higher score indicates positive adjustment, while a lower score indicates negative adjustment. The SDQ is used as a screening tool for researchers and clinicians for the presence of adjustment problems and psychiatric disorders. The questionnaire takes about 5 to 10 minutes to complete. Responders note their answer for each SDQ item on a three-point Likert-type scale $(0=$ not true, $1=$ somewhat true, $2=$ certainly true $)$. Scores are classified into normal, borderline, and abnormal adjustment categories. Parent Total Scores are classified as such, 0-13 "normal," 14-16 "borderline," 17-40 "abnormal." Teacher Total Scores are classified as such, 011 "normal," 12-15 "borderline," 16-40 "abnormal" (see Table 3 for clinical cut-off scores, p. 38). The cut-off scores for the parent and teacher were chosen such that 
Table 3

SDQ clinical cut-off scores

Scores

\begin{tabular}{lll}
\hline Normal & Borderline $\quad$ Abnormal \\
\hline
\end{tabular}

Parent Completed

Emotional Problems

0-3

4

5-10

Conduct Problems

$0-2$

3

4-10

Hyperactivity

$0-5$

6

7-10

Peer Social Problems

$0-2$

3

4-10

Prosocial Behaviours

6-10

5

$0-4$

Total Score

0-13

14-16

$17-40$

Teacher Completed

Emotional Problems

$0-4$

5

6-10

Conduct Problems

$0-2$

3

4-10

Hyperactivity

$0-5$

6

7-10

Peer Social Problems

0-3

4

5-10

Prosocial Behaviours

6-10

5

0-4

Total Score

0-11

$12-15$

$16-40$

Note. SDQ = Strengths and Difficulties Questionnaire. From Youthinmind Ltd. (n.d). SDQ: Information for researchers and professionals about the Strengths \& Difficulties Questionnaires. Retrieved July 22, 2012, from http://www.sdqinfo.com/py/ /sdqinfo/c0.py. Copyright (n.d.) by Youthinmind Ltd. Adapted with permission of the author. 
roughly $80 \%$ of the children in the general population are classified as having normal adjustment, 10 $\%$ are classified as having borderline adjustment, and $10 \%$ are classified as having abnormal adjustment (Goodman, 1997).

Strengths and Difficulties Questionnaire reliability. Internal consistency of the questionnaire has been shown to be satisfactory, with an alpha coefficient of .73. The crossinformant correlation, meaning the level or agreement between the scores of the parents and teachers, has also been shown to be acceptable, with an alpha coefficient of .34 (Goodman, 2001). Retest reliability has been evidenced after four to six months with a Cronbach alpha of .72 (Bourdon, Goodman, Rae, Simpson, \& Koretz, 2005).

Strengths and Difficulties Questionnaire validity. Correlations between the subscales are low, $r=.17$ and .41 , meaning that the subscales measure separate scales of behaviours (Muris, Meesters, \& van den Berg, 2003). Concurrent validity has been show with similar questionnaires such as the Child Behaviour Checklist (Goodman, 1999), $r=.87$ and the Rutters Questionnaire (Goodman, 1997), $r=.92$.

Piers-Harris Self-Concept Scale-Second Edition (PHSCS-2). The PHSCS-2 is a 60 item self-report yes/no questionnaire designed for 7-18 year old children (see Appendix G; Piers, Harris, \& Herzberg, 2002). There are six domain scales which measure different aspects of self-concept. Some of the items are included in more than one domain:

Scale 1. Behaviour adjustment measures the presence of problem behaviours at home and school (items 12, 13, 14, 18, 19, 20, 27, 30, 36, 38, 45, 48, 58).

Scale 2. Intellectual and school status measures the child's assessment of his/her intellectual abilities and school performance (items 5, 7, 12, 16, 18, 21, 22, 24, 25, 26, 34, 39, 43, 50, 52, 54). 
Scale 3. Physical appearance and attributes measures self-perception of physical appearance (items $5,8,9,15,26,33,39,44,45,49,54)$.

Scale 4. Freedom from anxiety measures anxious and depressive moods (items 4, 6, 7, 8, 10, 17, $23,29,31,32,35,40,56,59)$.

Scale 5. Popularity measures assessment of social functioning such as self-perceived popularity, ability to make friends, and inclusion in games and sports (items 1, 3, 6, 11, 32, 37, 39, 41, 47, $51,54,57)$.

Scale 6. Happiness and satisfaction measures general feelings of happiness and satisfaction with life (items 2, 8, 28, 31, 35, 40, 42, 49, 53, 60).

Higher scores indicate a positive self-concept whereas lower scores indicate a negative selfconcept. Scores of 39 or less indicate a below average self-concept. Scores between 40 and 60 are considered average, reflecting a positive self-concept, and scores above 61 indicate an above average self-concept. The scale takes approximately 15 minutes to complete (Piers \& Herzberg, 2002).

Piers-Harris Self-Concept Scale-Second Edition reliability. Internal consistency for the all the scales on the PHSCS-2 is high, with an average alpha coefficient of .91 (Piers \& Herzberg, 2002). The inter-scale correlation for the instrument is at .44, which indicates that the scales measure separate concepts (Cooley \& Ayres, 1988). Test-retest reliability has been shown to be adequate, at .75 (Platten \& Williams, 1981).

Piers-Harris Self-Concept Scale-Second Edition validity. Convergent validity of the instrument has been demonstrated with a similar questionnaire, the Coopersmith Self-Esteem Inventory, with an alpha coefficient of .78 (Franklin, Duley, Rousseau, \& Sabers, 1981). The scales in the PHSCS-2 also correlate significantly, $r=.22$, with similar scales from other instruments such 
as the Classroom Behaviour Rating Scale, which measures teachers' ratings of students' adjustment (Sun, 2005).

\section{Results}

\section{Part 1: Gifted Children}

To answer the first research objective regarding what type of parenting styles parents of gifted children use, the mean scores of the three parenting style subscales scores were calculated. An alpha level of .05 was used for all statistical tests.

A reliability analysis was conducted first to test the internal consistency of the PAQ-R. This was done to ensure that each item within a subscale measured the intended parenting style. Cronbach's alpha coefficients were calculated for the three samples of the study, the total sample, the gifted sample, and the nongifted sample. A coefficient was calculated for each subscale (i.e., each parenting style) to determine how closely the items in each subscale are related to the parenting style it is supposed to measure. The results are displayed in Table 4 and 5 (p. 42).

Clark and Watson (1995) indicated that acceptable reliability coefficients are in the .60s or above. As shown, the authoritarian and permissive scales present acceptable levels of internal consistency, whereas the authoritative scale for the mothers in the total and gifted sample and for fathers in the gifted sample present alpha coefficients in the $.50 \mathrm{~s}$. This means that the items composing the authoritative scale are not as closely related to the construct of authoritative parenting style.

In order to increase the internal consistency of the authoritative subscale, a PAQ-R item was removed thus increasing the alpha coefficient value. The reliability analysis showed that by removing item 8 of the authoritative subscale, which was "I direct the activities and decisions of my 
Table 4

Cronbach's alpha coefficients for the PAQ-R subscales completed by mothers

\begin{tabular}{lccc}
\hline $\begin{array}{c}\text { VARIABLES } \\
\text { Parenting Styles }\end{array}$ & $\begin{array}{c}\text { Total Sample } \\
(n=100)\end{array}$ & $\begin{array}{c}\text { Gifted Sample } \\
(n=48)\end{array}$ & $\begin{array}{c}\text { Nongifted Sample } \\
(n=52)\end{array}$ \\
$\begin{array}{l}\text { Authoritarian } \\
\text { Authoritative }\end{array}$ & 0.82 & 0.83 & 0.80 \\
Permissive & $0.57(0.66)^{\mathrm{a}}$ & $0.50(0.62)^{\mathrm{a}}$ & 0.63 \\
& 0.76 & 0.77 & 0.74 \\
\hline
\end{tabular}

Note. PAQ-R = Parental Authority Questionnaire-Revised.

${ }^{a}$ corrected alpha coefficient.

Table 5

Cronbach's alpha coefficients for the PAQ-R subscales completed by fathers

VARIABLES

Parenting Styles
Total Sample

$$
(n=64)
$$

Gifted Sample

$(n=33)$
Nongifted Sample

$$
(n=31)
$$
Authoritarian
0.72
0.75
0.70
Authoritative
0.61
$0.57(0.61)^{\mathrm{a}}$
0.64
Permissive
0.70
0.70
0.73

Note. PAQ-R = Parental Authority Questionnaire-Revised.

${ }^{a}$ corrected alpha coefficient. 
children by talking with them and using rewards and punishments," the alpha coefficients were increased to an acceptable level of .60 or above. The same reliability test was done for the SDQ and PHSCS-2 questionnaires, all subscales demonstrated alpha levels of .60 or above.

Following these corrections to the PAQ-R, the mean scores of the parenting styles of both mothers and fathers of the total gifted sample are displayed in Figure 1 (p. 44). First, repeated measure analyses were conducted to verify if there is a significant difference between the three parenting style mean scores of mothers in the gifted sample. Mauchly's Test of Sphericity was conducted to determine whether the assumption of sphericity (i.e., equal variance within the same sample) was violated and hence the $F$ statistic needed to be corrected. A significant value for this test indicates that the assumption has been violated. Moreover, to identify the size of any observed effects, the partial eta squared ratio, $\eta_{\mathrm{p}}{ }^{2}$, was included in the results. The partial eta squared value discloses the size of the difference between two scores. According to Stevens (2002), a large effect is .14 , a medium effect is .06, and a small effect is .01 .

Mothers' parenting style scores produced a chi-square with an associated alpha level of .05 or less, $\chi^{2}(2, n=48)=18.14, p=.000$, thus the assumption of sphericity was violated. The HuynhFeldt epsilon value was used to adjust the degrees of freedom and the corrected $F$ value was used. A significant difference was found between the three mean parenting style scores of the mothers, $F(1.55,3665.73)=78.79, p=.000$. An effect size value of $\eta_{\mathrm{p}}{ }^{2}=.63$ indicates a large significant difference. Pairwise comparisons (Bonferroni) were done to verify where the significant difference between the three parenting style mean scores lies. The mean score for mothers' authoritative parenting style $(M=38.69, S D=3.33)$ was significantly higher than the mean score for mothers' authoritarian $(M=28.65, S D=6.62)$ and permissive $(M=23.58, S D=5.56)$ parenting styles. In addition, mothers' mean authoritarian score was significantly higher than the mean permissive 


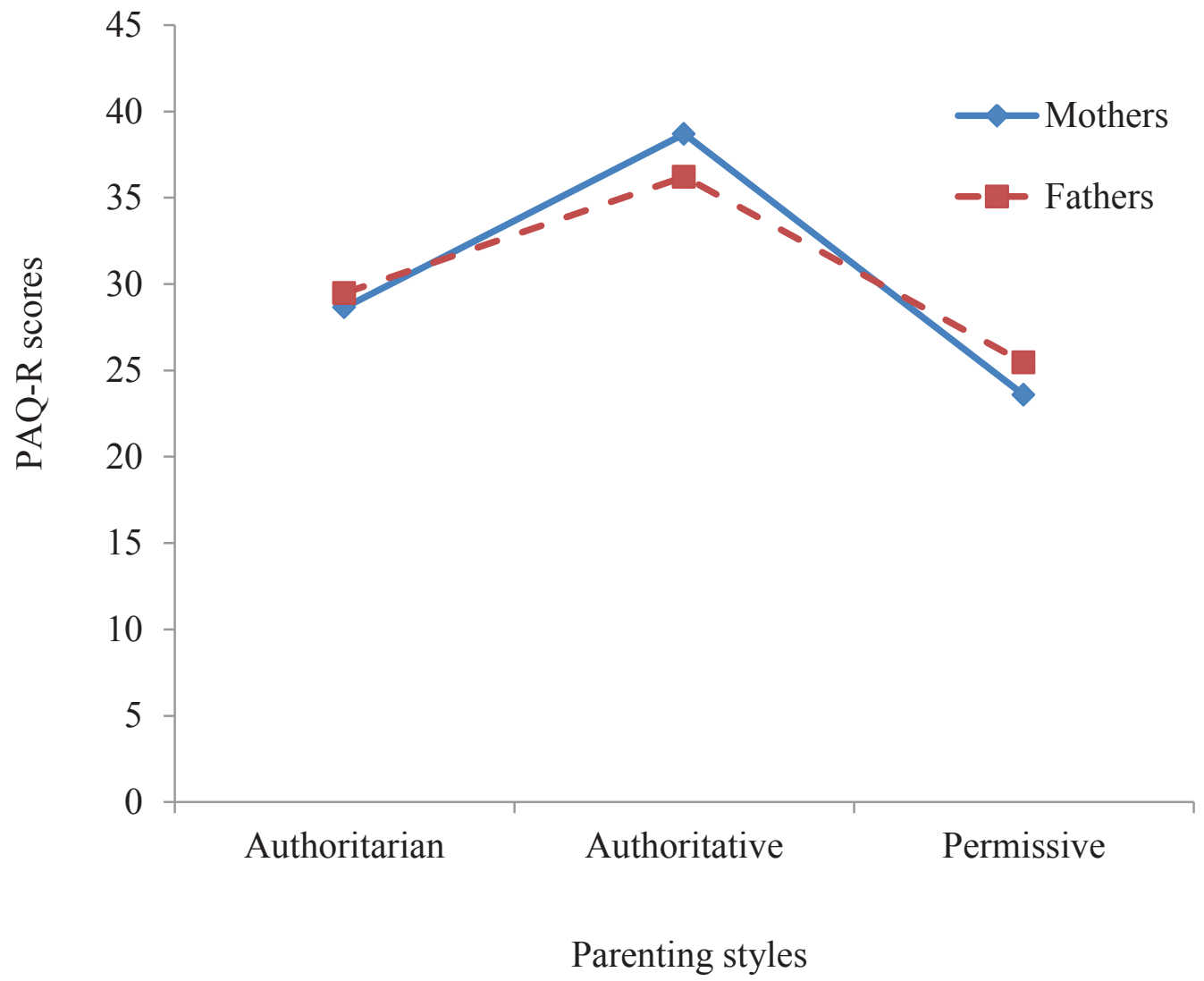

Figure 1. Mean scores of the PAQ-R (Parental Authority Questionnaire-Revised) subscales of mothers and fathers of gifted children. 
score. The same was done for fathers in the gifted sample.

For the fathers, Mauchly's Test of Sphericity produced a chi-square with an associated alpha level of .05 or more, thus sphericity was not violated. A significant difference was found between the three mean parenting style scores of the fathers, $F(2,974.74)=46.22, p=.000, \eta_{\mathrm{p}}{ }^{2}=.59$. Again, using pairwise comparisons, the three mean parenting style scores were found to be significantly different from each other. The mean score for fathers' authoritative parenting style ( $M=36.21, S D$ $=2.74)$ was significantly higher than the mean scores for fathers' authoritarian $(M=29.48, S D=$ 4.85) and permissive $(M=25.45, S D=4.58)$ parenting styles. In addition, fathers' mean authoritarian score was significantly higher than the mean permissive score. For both mothers and fathers of gifted children, the highest scores were for the authoritative parenting style followed by the authoritarian and permissive parenting styles.

Paired $t$-tests were also computed to check for significant differences in the mean scores on a parenting style between the mothers and fathers of gifted children. In addition to the $t$-tests, Cohen's $d$ statistic was computed to determine the effect size of the significant results in order to understand the magnitude of the difference between the two means. Cohen's $d$ of .80 is considered large, a $d$ of .50 is considered medium, and a $d$ of .20 is considered small (Cohen, 1988).

Significant differences were found for authoritative parenting style mean scores only, $t(32)$ 3.00, $p=.01, d=1.06$. Using Cohen's statistic, a $d=1.06$ is considered a large effect size. Mothers of gifted children scored significantly higher on the authoritative parenting style than fathers of gifted children (see Table 6, p. 46).

The second research objective was to identify the parenting style of parents of gifted children with positive and negative adjustment. To do so, the gifted sample was divided according to the presence of SDQ total and subscales borderline and clinical range scores. Two groups of 
Table 6

Means (and standard deviations) of the PAQ-R scores for mothers and fathers of the gifted sample

\begin{tabular}{|c|c|c|c|}
\hline VARIABLES & $\begin{array}{l}\text { Mothers } \\
(n=33)\end{array}$ & $\begin{array}{l}\text { Fathers } \\
(n=33)\end{array}$ & $\begin{array}{c}\text { Statistic } \\
t\end{array}$ \\
\hline Parenting Styles & Mean & Mean & \\
\hline $\begin{array}{l}\text { Authoritarian } \\
\text { (Standard deviation) }\end{array}$ & $\begin{array}{l}29.33 \\
(6.59)\end{array}$ & $\begin{array}{l}29.48 \\
(4.85)\end{array}$ & $-0.13 \mathrm{~ns}$ \\
\hline $\begin{array}{l}\text { Authoritative } \\
\text { (Standard deviation) }\end{array}$ & $\begin{array}{l}38.15 \\
(3.58)\end{array}$ & $\begin{array}{l}36.21 \\
(2.74)\end{array}$ & $3.00 * *$ \\
\hline $\begin{array}{l}\text { Permissive } \\
\text { (Standard deviation) }\end{array}$ & $\begin{array}{l}23.79 \\
(5.50)\end{array}$ & $\begin{array}{l}25.45 \\
(4.58)\end{array}$ & $-1.56 \mathrm{~ns}$ \\
\hline
\end{tabular}

Note. PAQ-R = Parental Authority Questionnaire-Revised. ns = not significant.

${ }^{*} p \leq .05 .{ }^{* *} p \leq .01 .{ }^{* * *} p \leq .001$. 
gifted children were thus formed: one group identified as having those scores and another group identified as not having them.

Nineteen of the 48 gifted children were identified by their mothers as having peer social problem scores in the abnormal range with a mean score of $4.32(S D=1.57)$. Fourteen fathers of these 19 children completed the SDQ. They also reported peer social problem scores with a mean score of $3.50(S D=2.25)$, which is in the borderline range. Fourteen teachers of these children completed the SDQ. In contrast to the parents, they reported low peer social problem scores with a mean score of $2.07(S D=1.98)$. In summary, mothers and fathers reported borderline to abnormal peer social problems with no significant differences between their reported means, $t(13)=1.91, p=$ .08 , while the teachers did not report any peer social problems. The mothers, fathers, and teachers of this subsample reported normal range mean scores for these children on the prosocial behaviours scale (i.e., "strengths" scale). This means that, although mothers and fathers rated their gifted children as having peer social problems such as preferring to play alone rather than with other children and getting along better with adults than with other youth, they did not indicate them as manifesting low prosocial behaviours, such as not sharing with other children (see Table 7, p. 48).

In contrast, the subsample of gifted children identified by their mothers as having peer social problems on the SDQ reported mean scores of 40 or higher on all the PHSCS-2 domain scales, including the popularity scale, reflecting an overall positive self-concept. Their mothers and fathers stated that they were having peer social problems, whereas the gifted children themselves reported average popularity scores and average scores in all the other self-concept domain scales (see Table 8, p. 49).

A profile analysis was conducted with the divided gifted sample via a multivariate repeated measures analysis. The profile analysis provides statistical information in the form of a graph to 
Table 7

Inter-rater means (and standard deviations) of the $S D Q$ scores of the gifted sample identified as having peer social problems

\begin{tabular}{|c|c|c|c|}
\hline VARIABLES & Mothers & Fathers & Teachers \\
\hline SDQ Total and Subscale Mean Scores & $(n=19)$ & $(n=14)$ & $(n=14)$ \\
\hline $\begin{array}{l}\text { Total Means } \\
\text { (Standard deviation) }\end{array}$ & $\begin{array}{l}12.21 \\
(6.43)\end{array}$ & $\begin{array}{c}9.21 \\
(5.52)\end{array}$ & $\begin{array}{c}5.43 \\
(4.72)\end{array}$ \\
\hline $\begin{array}{l}\text { Emotional Problems Means } \\
\text { (Standard deviation) }\end{array}$ & $\begin{array}{c}2.89 \\
(2.83)\end{array}$ & $\begin{array}{c}2.79 \\
(1.93)\end{array}$ & $\begin{array}{c}0.71 \\
(1.38)\end{array}$ \\
\hline $\begin{array}{l}\text { Conduct Problems Means } \\
\text { (Standard deviation) }\end{array}$ & $\begin{array}{c}1.74 \\
(1.37)\end{array}$ & $\begin{array}{c}1.00 \\
(1.30)\end{array}$ & $\begin{array}{c}0.50 \\
(0.76)\end{array}$ \\
\hline $\begin{array}{l}\text { Hyperactivity Means } \\
\text { (Standard deviation) }\end{array}$ & $\begin{array}{c}3.26 \\
(3.12)\end{array}$ & $\begin{array}{c}1.93 \\
(1.73)\end{array}$ & $\begin{array}{c}1.86 \\
(2.32)\end{array}$ \\
\hline $\begin{array}{l}\text { Peer Social Problems Means } \\
\text { (Standard deviation) }\end{array}$ & $\begin{array}{l}4.32^{\mathrm{a}} \\
(1.57)\end{array}$ & $\begin{array}{l}3.50^{\mathrm{b}} \\
(2.25)\end{array}$ & $\begin{array}{c}2.07 \\
(1.98)\end{array}$ \\
\hline $\begin{array}{l}\text { Prosocial Behaviours Means } \\
\text { (Standard deviation) }\end{array}$ & $\begin{array}{c}8.53 \\
(1.50)\end{array}$ & $\begin{array}{c}8.07 \\
(1.33)\end{array}$ & $\begin{array}{l}7.07 \\
(2.62)\end{array}$ \\
\hline
\end{tabular}

Note. SDQ = Strength and Difficulties Questionnaire.

${ }^{a}$ abnormal range. borderline range. 
Table 8

Means (and standard deviations) of the PHSCS-2 scores reported by gifted children identified as having peer social problems

VARIABLES

PHSCS-2 Total and Subscale Mean Scores

\section{Gifted Sample}

$$
(n=19)
$$

Total Mean

(Standard deviation)

Behaviour Mean

(Standard deviation)

Intellectual Mean

(Standard deviation)

Physical Appearance Mean

(Standard deviation)

Freedom from Anxiety Mean

(Standard deviation)

Popularity Mean

(Standard deviation)

Happiness Mean

(Standard deviation)
53.16

(11.49)

52.47

$(9.58)$

53.42

(6.74)

49.11

(9.13)

54.63

(9.84)

48.42

(9.68)

46.68

(5.68)

Note. PHSCS-2 = Piers-Harris Self-Concept Scale-Second Edition. Scores less than 39 indicate a low self-concept; scores between 40-60 indicate an average self-concept; scores above 61 indicate an above average self-concept. 
determine if there is significant difference between groups on a certain variable. The two groups compared were mothers of gifted children with and without peer social problems. Their mean scores on the PAQ-R were compared to determine if one group scored significantly higher on a certain parenting style subscale. For all profile analyses, Mauchly's Test of Sphericity was used to determine whether the assumption of sphericity was violated, Box's Test of Equality of Covariance Matrices was used to confirm normal distribution between the groups and Levene's Test for Equality of Variance was used to confirm equal variability of the scores between the two groups. Nonsignificant values of these tests indicate that the test assumptions were met.

Mothers' parenting style scores produced a chi-square with an associated alpha level of .05 or less, $\chi^{2}(2, n=48)=17.22, p=.000$, which violates the assumption of sphericity. The HuynhFeldt epsilon value was used to adjust the degrees of freedom and the $F$ value. No significant differences were then found between the mean scores on the three parenting style subscales between the two groups of mothers, $F(1.60,35.14)=0.77, p=.44$. In summary, the parenting style profile did not differ between mothers who said their gifted children had peer social problems and mothers of gifted children who said they did not (see Figure 2, p. 51).

A same profile analysis was done between fathers of gifted children who said their gifted children had peer social problems and fathers who said their gifted children had none. As with the mothers, no significant differences were found between the mean scores on the three parenting style subscales between the two groups of fathers, $F(2,1.76)=0.08, p=.92$ (see Figure 3, p. 52).

Correlations. To answer the third research objective, what type of parenting style is related to positive or negative adjustment in gifted children, Pearson correlations were conducted to establish whether there is a link between adjustment scores of gifted children with and without peer social problems (as perceived by the parents on the SDQ) and the three parenting styles scores. No 


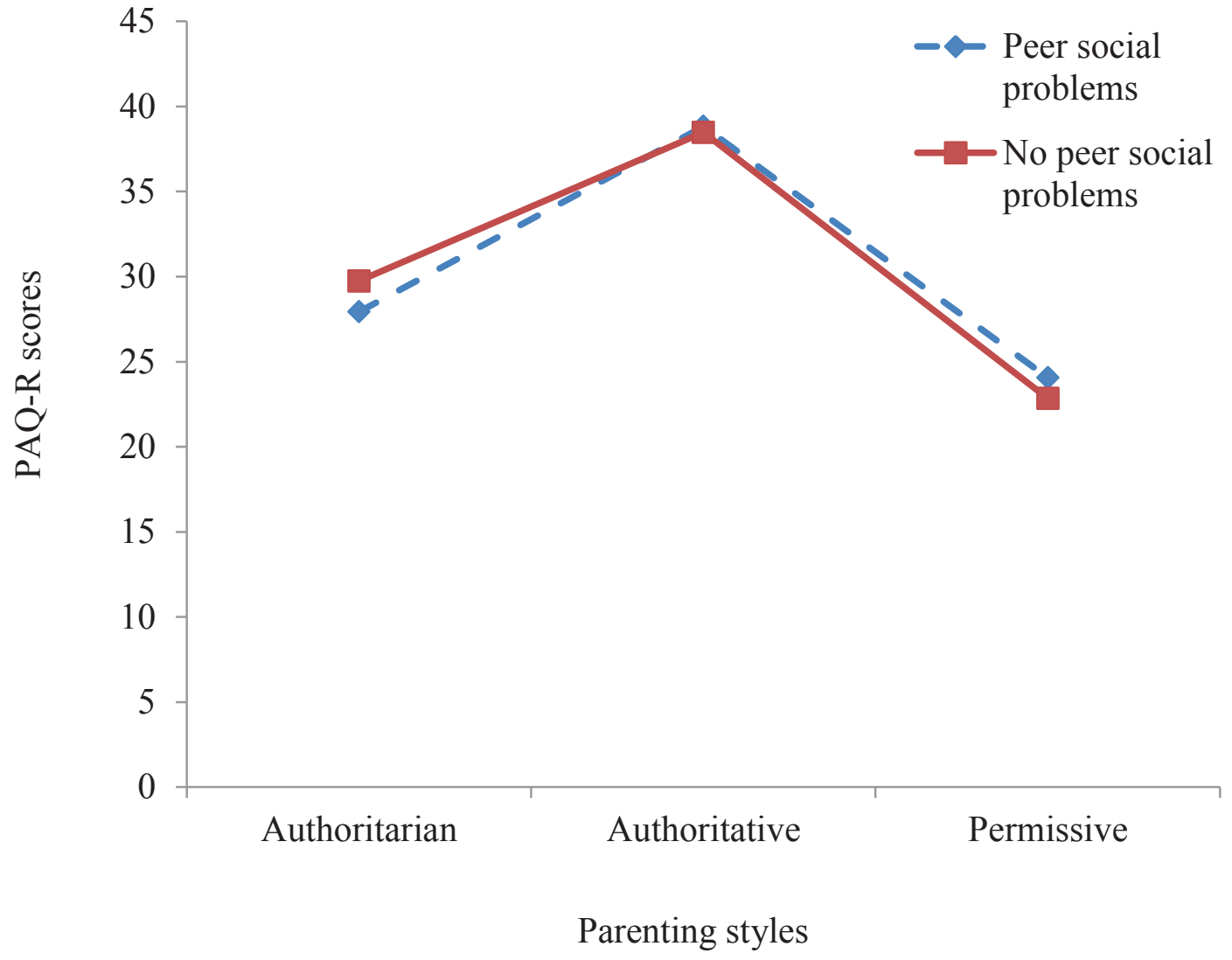

Figure 2. Mean scores of the PAQ-R (Parental Authority Questionnaire-Revised) subscales of mothers of gifted children with and without peer social problems. 


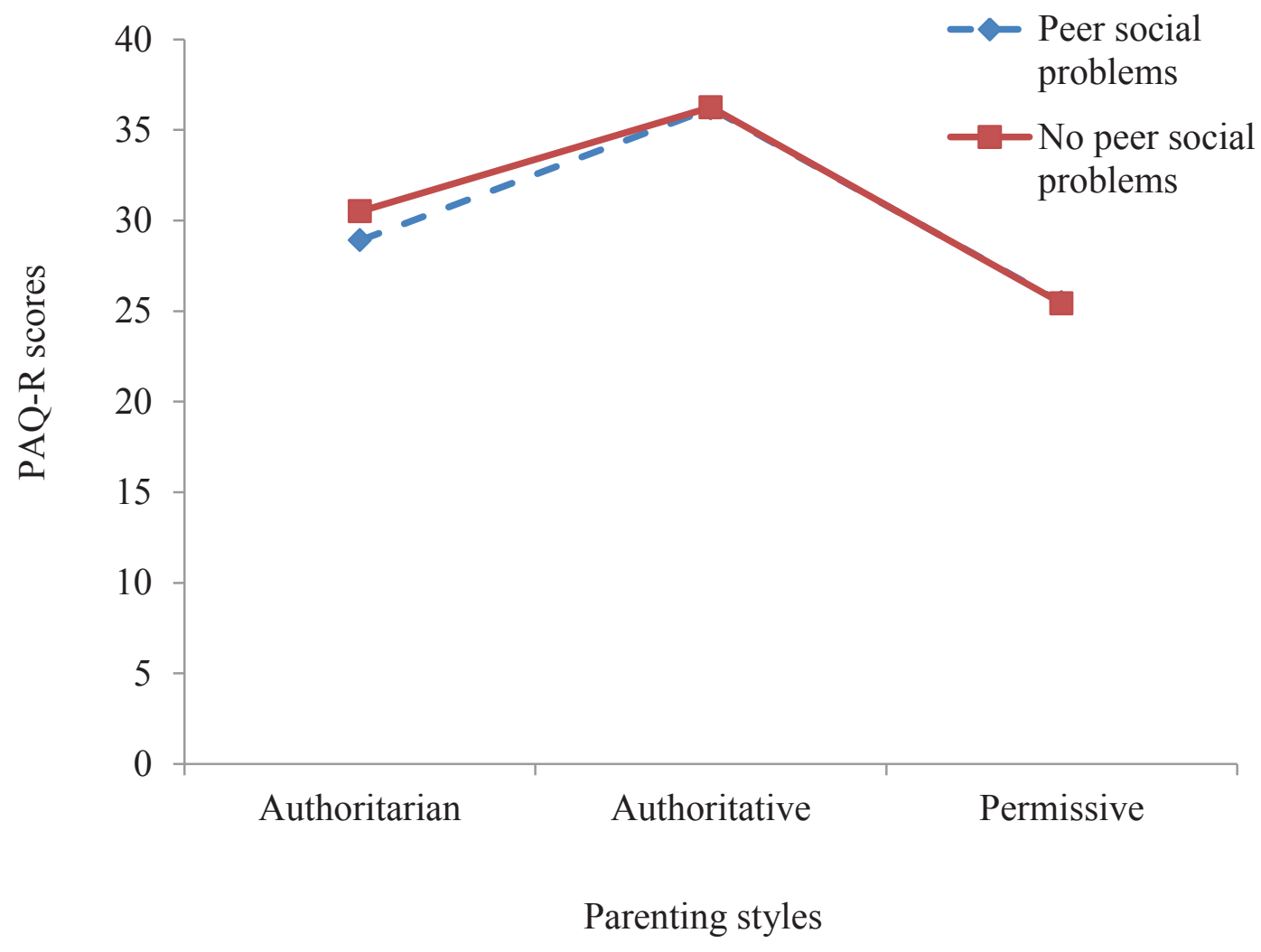

Figure 3. Mean scores of the PAQ-R (Parental Authority Questionnaire-Revised) subscales of fathers of gifted children with and without peer social problems. 
correlation analyses were done between parenting styles and the PHSCS-2 scores since no selfconcepts scores were detected in the low range.

First, with the subsample of gifted children whose mothers said they had peer social problems, a significant positive correlation was found between mothers' authoritative parenting style and the conduct problems scores, $r=.52, n=19, p=.02$. Higher authoritative parenting scores in mothers were linked to higher conduct problem scores. A significant positive correlation was found between fathers' authoritarian parenting style and total scores in gifted children identified as having peer social problems, $r=.54, n=14, p=.05$.

Second, a significant negative correlation was found between mothers' authoritarian parenting style and conduct problem scores in gifted children identified as not having peer social problems, $r=-.45, n=29, p=.02$. This indicates that higher authoritarian parenting scores in mothers were linked to lower conduct problem scores in gifted children identified as not having peer social problems.

No significant correlations were found between fathers' parenting style and gifted children identified as not having peer social problems.

\section{Part 2: Comparative Analyses}

To answer the fourth research objective and confirm whether gifted children have better adjustment than nongifted children, comparative analyses were conducted on adjustment levels of the gifted $(n=48)$ and the nongifted sample $(n=52)$. The mean scores and standard deviations for each group were derived for each questionnaire. The descriptive and inferential statistics are presented in Tables 9-11 (pp. 54-56) for the SDQ scores (mother, father, and teacher responders), and in Table 12 (p. 57) for the PHSCS-2 scores. None of the mean scores of the overall gifted and 
Table 9

Means (and standard deviations) of mothers' $S D Q$ scores for gifted and nongifted children

VARIABLES

SDQ Total and Subscale Mean Scores

$\begin{array}{ccc}\text { Gifted } & \text { Nongifted } & \text { Statistic } \\ \text { Sample } & \text { Sample } & t\end{array}$

$(n=48) \quad(n=52)$
Total Means

(Standard deviation)

Emotional Problems Means

(Standard deviation)

Conduct Problems Means

(Standard deviation)

Hyperactivity Means

(Standard deviation)

Peer Social Problems Means

(Standard deviation)

Prosocial Behaviours Means

(Standard deviation)
9.06

$(5.80)$

2.40

(2.47)

1.29

(1.32)

3.00

(2.70)

2.25

(2.04)

8.63

(1.61)
8.00

(5.55)

2.13

(2.05)

1.02

(1.20)

3.29

(2.70)

1.73

(2.04)

8.44

(1.73)
0.94 ns

$0.58 \mathrm{~ns}$

$1.08 \mathrm{~ns}$

$-0.53 \mathrm{~ns}$

$1.27 \mathrm{~ns}$

$0.55 \mathrm{~ns}$

Note. $\mathrm{SDQ}=$ Strengths and Difficulties Questionnaire. $\mathrm{ns}=$ not significant. 
Table 10

Means (and standard deviations) of fathers' $S D Q$ scores for gifted and nongifted children

VARIABLES

SDQ Total and Subscale Mean Scores

$\begin{array}{ccc}\text { Gifted } & \text { Nongifted } & \text { Statistic } \\ \text { Sample } & \text { Sample } & t\end{array}$

$(n=33) \quad(n=31)$
Total Means

(Standard deviation)

Emotional Problems Means

(Standard deviation)

Conduct Problems Means

(Standard deviation)

Hyperactivity Means

(Standard deviation)

Peer Social Problems Means

(Standard deviation)

Prosocial Behaviours Means

(Standard deviation)
7.67

(4.33)

2.42

(2.00)

0.85

(1.03)

2.15

(2.03)

2.30

(2.00)

8.21

(1.36)
8.26

(5.85)

1.90

(2.12)

0.84

(1.07)

3.71

(2.70)

1.97

(2.46)

8.23

(1.71)
$-0.46 \mathrm{~ns}$

$1.02 \mathrm{~ns}$

(1)

$0.04 \mathrm{~ns}$$$
0.04 \mathrm{~ns}
$$

$-2.63^{* *}$

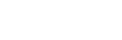

$0.60 \mathrm{~ns}$

$-0.04 \mathrm{~ns}$

Note. SDQ = Strengths and Difficulties Questionnaire. $\mathrm{ns}=$ not significant.

$* p \leq .05 . * * p \leq .01 . * * * p \leq .001$. 
Table 11

Means (and standard deviations) of teachers' SDQ scores for gifted and nongifted children

\begin{tabular}{|c|c|c|c|}
\hline VARIABLES & $\begin{array}{l}\text { Gifted } \\
\text { Sample }\end{array}$ & $\begin{array}{l}\text { Nongifted } \\
\text { Sample }\end{array}$ & $\begin{array}{c}\text { Statistic } \\
t\end{array}$ \\
\hline SDQ Total and Subscale Mean Scores & $(n=36)$ & $(n=31)$ & \\
\hline $\begin{array}{l}\text { Total Means } \\
\text { (Standard deviation) }\end{array}$ & $\begin{array}{c}5.28 \\
(4.19)\end{array}$ & $\begin{array}{c}7.61 \\
(5.57)\end{array}$ & $-1.95 \mathrm{~ns}$ \\
\hline $\begin{array}{l}\text { Emotional Problems Means } \\
\text { (Standard deviation) }\end{array}$ & $\begin{array}{c}0.94 \\
(1.53)\end{array}$ & $\begin{array}{l}2.35 \\
(2.75)\end{array}$ & $-2.54 * *$ \\
\hline $\begin{array}{l}\text { Conduct Problems Means } \\
\text { (Standard deviation) }\end{array}$ & $\begin{array}{c}0.50 \\
(0.70)\end{array}$ & $\begin{array}{c}0.94 \\
(1.24)\end{array}$ & $-1.74 \mathrm{~ns}$ \\
\hline $\begin{array}{l}\text { Hyperactivity Means } \\
\text { (Standard deviation) }\end{array}$ & $\begin{array}{c}1.81 \\
(2.45)\end{array}$ & $\begin{array}{c}3.26 \\
(3.26)\end{array}$ & $-2.08 *$ \\
\hline $\begin{array}{l}\text { Peer Social Problems Means } \\
\text { (Standard deviation) }\end{array}$ & $\begin{array}{c}1.92 \\
(1.86)\end{array}$ & $\begin{array}{c}1.71 \\
(1.90)\end{array}$ & $0.45 \mathrm{~ns}$ \\
\hline $\begin{array}{l}\text { Prosocial Behaviours Means } \\
\text { (Standard deviation) }\end{array}$ & $\begin{array}{c}7.47 \\
(2.35)\end{array}$ & $\begin{array}{c}7.13 \\
(1.73)\end{array}$ & $0.67 \mathrm{~ns}$ \\
\hline
\end{tabular}

Note. $\mathrm{SDQ}=$ Strengths and Difficulties Questionnaire. $\mathrm{ns}=$ not significant.

${ }^{*} p \leq .05 . * * p \leq .01 . * * * p \leq .001$. 
Table 12

Means (and standard deviations) of children's PHSCS-2 scores

\begin{tabular}{|c|c|c|c|}
\hline VARIABLES & $\begin{array}{l}\text { Gifted } \\
\text { Sample }\end{array}$ & $\begin{array}{l}\text { Nongifted } \\
\text { Sample }\end{array}$ & $\begin{array}{c}\text { Statistic } \\
t\end{array}$ \\
\hline $\begin{array}{l}\text { PHSCS-2 Total and Subscale } \\
\text { Mean Scores }\end{array}$ & $(n=48)$ & $(n=52)$ & \\
\hline $\begin{array}{l}\text { Total Means } \\
\text { (Standard deviation) }\end{array}$ & $\begin{array}{l}52.94 \\
(9.59)\end{array}$ & $\begin{array}{l}53.75 \\
(9.64)\end{array}$ & $-0.42 \mathrm{~ns}$ \\
\hline $\begin{array}{l}\text { Behaviour Means } \\
\text { (Standard deviation) }\end{array}$ & $\begin{array}{l}52.69 \\
(8.47)\end{array}$ & $\begin{array}{l}53.98 \\
(8.95)\end{array}$ & $-0.74 \mathrm{~ns}$ \\
\hline $\begin{array}{l}\text { Intellectual Means } \\
\text { (Standard deviation) }\end{array}$ & $\begin{array}{l}53.21 \\
(6.55)\end{array}$ & $\begin{array}{l}52.21 \\
(8.06)\end{array}$ & $0.68 \mathrm{~ns}$ \\
\hline $\begin{array}{l}\text { Physical Appearance Means } \\
\text { (Standard deviation) }\end{array}$ & $\begin{array}{l}49.88 \\
(8.26)\end{array}$ & $\begin{array}{l}49.77 \\
(7.61)\end{array}$ & $0.07 \mathrm{~ns}$ \\
\hline $\begin{array}{l}\text { Freedom from Anxiety Means } \\
\text { (Standard deviation) }\end{array}$ & $\begin{array}{l}52.71 \\
(8.83)\end{array}$ & $\begin{array}{l}54.02 \\
(9.53)\end{array}$ & $-0.71 \mathrm{~ns}$ \\
\hline $\begin{array}{l}\text { Popularity Means } \\
\text { (Standard deviation) }\end{array}$ & $\begin{array}{l}50.13 \\
(8.46)\end{array}$ & $\begin{array}{l}49.35 \\
(8.07)\end{array}$ & $0.47 \mathrm{~ns}$ \\
\hline $\begin{array}{l}\text { Happiness Means } \\
\text { (Standard deviation) }\end{array}$ & $\begin{array}{l}47.40 \\
(6.73)\end{array}$ & $\begin{array}{l}50.67 \\
(6.81)\end{array}$ & $-2.42^{*}$ \\
\hline
\end{tabular}

Note. PHSCS-2 = Piers-Harris Self-Concept Scale-Second Edition. ns = not significant.

${ }^{*} \mathrm{p} \leq .05 . * * \mathrm{p} \leq .01 . * * * \mathrm{p} \leq .001$. 
nongifted samples fell into the borderline or abnormal SDQ range and low PHSCS-2 range.

Independent $t$-tests were conducted to examine any significant differences between the mean scores of the two samples. Equal variance between the mean scores of the two samples was confirmed with nonsignificant $F$ values of Levene's Test of Equality of Variance. No significant differences were found for the SDQ mean scores as reported by the mothers. Fathers of nongifted children reported a significantly higher mean score for them on the hyperactivity scale than fathers of gifted children, $t(62)=-2.63, p=.01, d=-.67$.

Teachers attributed significantly different mean scores to the two samples of children on the emotional problems and hyperactivity scales. For the emotion problems scores, Levene's Test for Equality of Variance showed a significant $F$ value of $F(65)=5.87, p=.02$, violating the homogeneity assumption. To correct this, the adjusted $t$-score and degrees of freedom were used. On these scales, teachers reported a significantly higher emotional problem mean score, $t(45.34)=$ $-2.54, p=.02, d=-.75$, and a significantly higher hyperactivity mean score, $t(65)=-2.08, p=.04, d$ $=-.52$, for nongifted children.

Both groups of children rated themselves as having an average self-concept in all domains on the PHSCS-2 with no significant difference between the mean scores, except in the happiness domain. Nongifted children reported a significantly higher mean score for happiness than gifted children, $t(98)=-2.42, p=.02, d=-.50$.

To answer the fifth research objective, to compare the parenting styles of parents of gifted children and nongifted children, a profile analysis was conducted. Mothers' parenting style mean scores produced a chi-square with an associated alpha level of .05 or less, $\chi^{2}(2, n=100)=22.95$, $p=.000$, violating the assumption of sphericity. Fathers' parenting style scores produced a chisquare with an associated alpha level of .05 or less, $\chi^{2}(2, n=64)=18.20, p=.000$, also violating 
the assumption of sphericity. The Huynh-Feldt epsilon values were used to adjust the degrees of freedom and the $F$ values. The results showed that there were no significant differences between the parenting styles of the two samples of mothers, $F(1.69,30.71)=0.78, p=.44$, and between the two samples of fathers, $F(1.65,2.25)=0.08, p=.89$. That is that the parenting styles mean scores do not differ between mothers of gifted and mothers of nongifted children nor between fathers of gifted and fathers of nongifted children. It appears that regardless of having gifted or nongifted children, parents report similar use of the three parenting styles (see Figures 4 and 5, pp. 60-61).

In addition, to verify if the parenting style profiles differed between mothers and fathers of nongifted children, paired $t$-test were conducted. Significant differences were found for authoritative parenting style means only, $t(30) 2.69, p=.01, d=.98$. Mothers of nongifted children scored significantly higher on the authoritative parenting style than did fathers of nongifted children (see Table 13, p. 62).

Correlations. To address the last research objective, to compare the associations between parenting style and adjustment in gifted and nongifted children, correlation analyses were conducted on both samples to find out if a certain parenting style is associated with higher or lower scores on the SDQ and PHSCS-2.

Strengths and Difficulties Questionnaire. For the gifted sample, a significant positive correlation was found between mothers' authoritative parenting style and conduct problem scores, $r$ $=.30, n=48, p=.04$. That is higher authoritative parenting scores in mothers were linked to higher conduct problem scores in gifted children. In contrast, a significant negative correlation was found with fathers' authoritative parenting style and conduct problems in nongifted children, $r=-.38, n=$ $31, p=.03$. For mothers with gifted children, an authoritative parenting style is related to more 


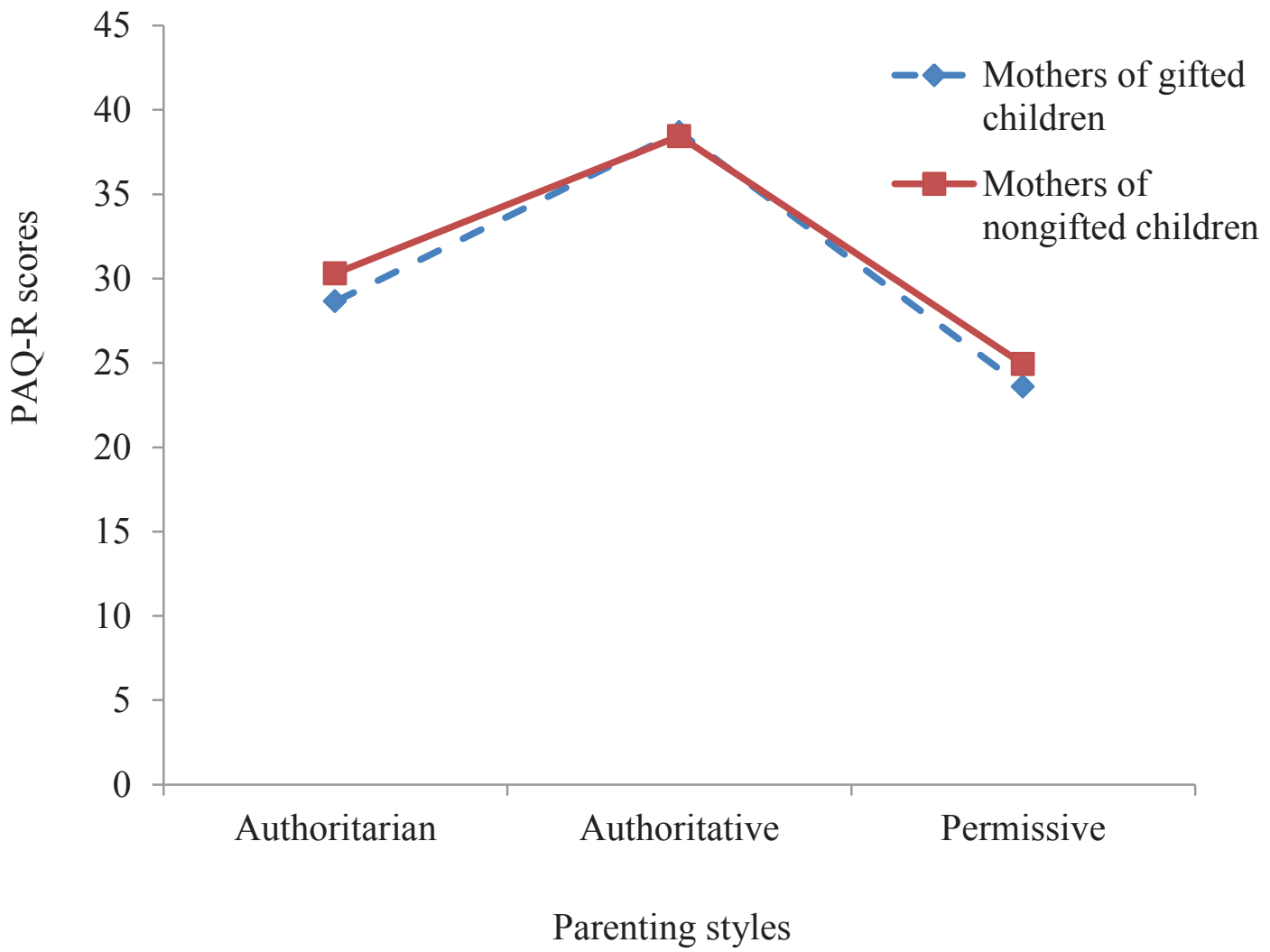

Figure 4. Mean scores of the PAQ-R (Parental Authority Questionnaire-Revised) subscales of mothers of gifted and nongifted children. 


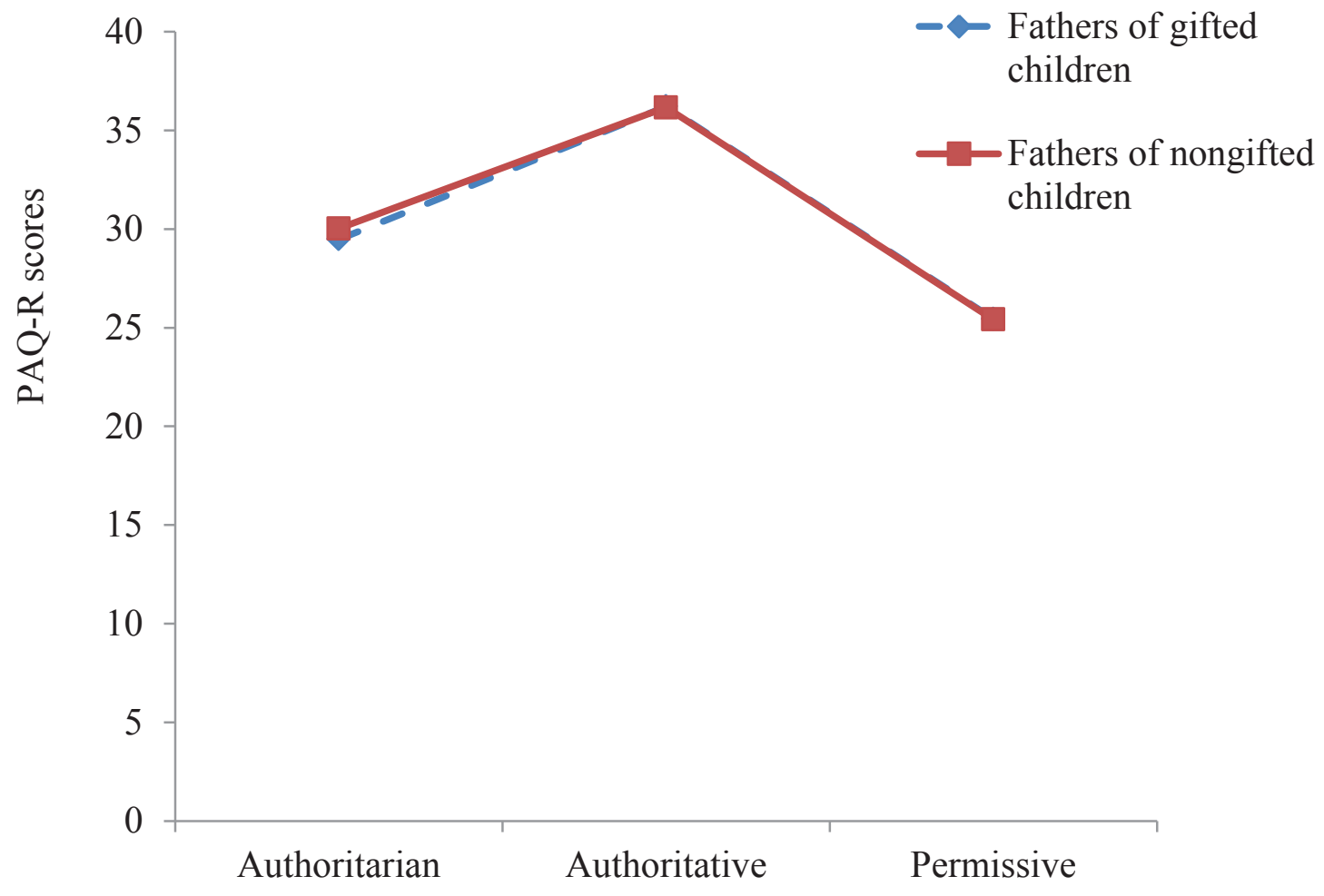

Parenting styles

Figure 5. Mean scores of the PAQ-R (Parental Authority Questionnaire-Revised) subscales of fathers of gifted and nongifted children. 
Table 13

Means (and standard deviations) of the PAQ-R scores for mothers and fathers of the nongifted sample

\begin{tabular}{|c|c|c|c|}
\hline VARIABLES & $\begin{array}{l}\text { Mothers } \\
(n=31)\end{array}$ & $\begin{array}{l}\text { Fathers } \\
(n=31)\end{array}$ & $\begin{array}{c}\text { Statistic } \\
t\end{array}$ \\
\hline Parenting Styles & Mean & Mean & \\
\hline $\begin{array}{l}\text { Authoritarian } \\
\text { (Standard deviation) }\end{array}$ & $\begin{array}{l}30.19 \\
(6.47)\end{array}$ & $\begin{array}{l}30.03 \\
(4.98)\end{array}$ & $0.17 \mathrm{~ns}$ \\
\hline $\begin{array}{l}\text { Authoritative } \\
\text { (Standard deviation) }\end{array}$ & $\begin{array}{l}38.13 \\
(3.40)\end{array}$ & $\begin{array}{l}36.16 \\
(3.43)\end{array}$ & $2.69 * *$ \\
\hline $\begin{array}{l}\text { Permissive } \\
\text { (Standard deviation) }\end{array}$ & $\begin{array}{l}24.42 \\
(5.82)\end{array}$ & $\begin{array}{l}25.42 \\
(5.04)\end{array}$ & $-0.82 \mathrm{~ns}$ \\
\hline
\end{tabular}

Note. PAQ-R = Parental Authority Questionnaire-Revised. ns = not significant.

${ }^{*} p \leq .05 .{ }^{* *} p \leq .01 . * * * p \leq .001$. 
conduct problems, whereas for fathers of nongifted children the authoritative parenting style is related to fewer conduct problems.

Piers-Harris Self-Concept Scale-Second Edition. For gifted children, it was found that mothers' authoritarian parenting style is linked to higher scores on the intellectual scale of the PHSCS-2, $r=.30, n=48, p=.04$. This would mean that higher authoritarian parenting scores in mothers are associated with higher intellectual self-concept scores in gifted children. Furthermore, a significant negative correlation was found between mothers' permissive parenting style and the intellectual scores, $r=-.37, n=48, p=.01$, the happiness scores, $r=-.29, n=48, p=.05$, and the total self-concept scores, $r=-.31, n=48, p=.03$. Therefore, higher permissive parenting scores in mothers are related to lower intellectual, happiness, and total self-concept scores in gifted children. For fathers of the gifted sample, a significant negative correlation was found between permissive parenting style and total self-concept scores, $r=-.38, n=33, p=.03$. This translates to fathers' permissive parenting style being connected to lower total self-concept scores in gifted children.

As for the nongifted sample, a significant negative correlation was found between mothers' authoritarian parenting and the happiness scores, $r=-.31, n=52, p=.03$. In other words, lower happiness scores are linked to higher authoritarian parenting scores in mothers with nongifted children. Similarly, a significant negative correlation was found with fathers' permissive parenting style and happiness scores, $r=-.36, n=31, p=.05$. Fathers' permissive parenting with nongifted children is connected to lower happiness scores.

\section{Additional Analyses}

An interrater reliability analysis using the interclass correlation coefficient (ICC) statistic was performed to determine consistency among the scores of the mothers, the fathers, and the 
teachers of gifted and nongifted children (see Table 14, p. 65). The Kappa statistic (Landis \& Koch, 1977) was used to determine the levels of agreement.

Gifted sample. The ICC for the SDQ scales were found to range from fair to moderate agreement between the mothers, father, and teachers, except for the conduct problems scale which was found to have slight agreement.

To identify where the level of disagreement lies between the three responders in the gifted sample on the conduct problems scale of the SDQ, the mean scores for this subscale of the mothers, fathers, and teachers were analyzed using repeated measures analysis. Mauchly's Test of Sphericity produced chi-squares with an associated alpha level of .05 or more, thus sphericity was not violated in these analyses.

A significant difference in the mean scores was found between the three responders, $F(2$, $3.93)=3.80, p=.03, \eta_{\mathrm{p}}{ }^{2}=.15$. Pairwise comparisons revealed the disagreement lay between the mothers and the teachers. Mothers rated gifted children as having a significantly higher conduct problem mean score $1.17(S D=1.37)$ than teachers $0.74(S D=1.05)$. Nonetheless, none of the SDQ mean scores are in the borderline or abnormal range.

Nongifted sample. The ICC for the SDQ scores for this sample varied from fair to substantial agreement, except for the prosocial behaviours scale which displayed slight agreement. A significant difference was found in the means scores between the three responders, $F(2,10.42)=$ $3.86, p=.03, \eta_{\mathrm{p}}{ }^{2}=.13$. Pairwise comparisons showed the disagreement was between the fathers and the teachers. Fathers rated nongifted children as having a significantly higher prosocial behaviour mean score $8.38(S D=1.72)$ than teachers $7.27(S D=1.80)$. Both scores fall in the normal range. 
Table 14

Level of agreement for mothers, fathers and teachers on the SDQ

\begin{tabular}{|c|c|c|}
\hline VARIABLES & $\begin{array}{c}\text { Gifted } \\
\text { Sample }\end{array}$ & $\begin{array}{c}\text { Nongifted } \\
\text { Sample }\end{array}$ \\
\hline SDQ Total Score and Subscales & $(n=23)$ & $(n=26)$ \\
\hline Total Score & 0.21 & 0.39 \\
\hline Emotional Problems & 0.40 & 0.27 \\
\hline Conduct Problems & 0.07 & 0.24 \\
\hline Hyperactivity & 0.57 & 0.35 \\
\hline Peer Social Problems & 0.26 & 0.70 \\
\hline Prosocial Behaviours & 0.51 & 0.17 \\
\hline
\end{tabular}

Note. SDQ = Strengths and Difficulties Questionnaire. Kappa reliability statistics are categorized as follows: $<0=$ poor agreement, $0.0-0.20=$ slight agreement, $0.21-0.40=$ fair agreement, $0.41-0.60=$ moderate agreement, $0.61-0.80=$ substantial agreement, $0.81-1.00=$ almost perfect agreement. 


\section{Summary of the Findings}

\section{Discussion}

The main goal of this study was to explore the relationship between parenting styles and adjustment problems of gifted children. Parents of gifted children stated that they use a predominantly authoritative parenting style. Several parents reported that their gifted children experience peer social problems. The profile analysis showed that the parenting styles did not differ between parents who said their gifted children had peer social problems and those who did not report this. Also, no relationship was detected between a particular parenting style and peer social problems in gifted children. This is a core finding of this study, indicating that parenting styles do not appear to be related to the reported presence or absence of peer social problems in gifted children. It is important though to note that this study found other adjustment problems, such as conduct problems, related to certain parenting styles.

Aside from the main results, other interesting findings emerged from this study. Parents reported that gifted children experience peer social problems, but the teachers and the children did not report any problems. It seems that parents, children, and teachers do not perceive the children in the same manner. Mothers and teachers of gifted children also disagreed about the level of conduct problems in gifted children. Previous studies using the SDQ reported that mothers and teachers agreed on the scores (Goodman, 1999; 2001). This was the first study to test the interrater agreement of the SDQ with three different responders: mothers, fathers, and teachers. By gathering several perspectives as this study has done, it enabled the identification of these perceptual discrepancies.

Another finding that emerged from this study is the contradictory information provided by the participants. To highlight this contradictory information, two examples of participants from this study will be provided. A 7-year-old girl scored a FSI of 141 on the WISC-IV, categorizing her as 
gifted. Subsequent to completing the IQ test and questionnaires, the mother of this child contacted the researcher to ask for help with her daughter's extreme shyness. The mother stated that her daughter consistently refused to speak to adults. In contrast to what the mother said, during the administration of the WISC-IV, the girl had initiated conversations and joked with the examiner about her school, classmates, and her favorite games. Another example is that of an 8-year-old boy with a FSI of 131. The mother reported herself as using a mainly authoritative parenting style. She sought consultation regarding her child's conduct and hyperactivity problems. During the consultation, the boy reported that his mother punished him frequently, disparaged, insulted, and threatened him. Hence, this information raises questions regarding the parenting styles reported by the parents and the perception of social behaviour of gifted children.

The present study also compared adjustment levels and parenting styles of the gifted and nongifted groups. According to the fathers and teachers, nongifted children were more hyperactive and had more emotional problems than gifted children, whereas the children said they had a better self-concept than gifted children. Parents of nongifted children reported using the three parenting styles in a similar manner to the parents of gifted children. Also with the parents of nongifted children, the authoritative parenting style was associated with positive child adjustment, while the authoritarian and permissive parenting styles were associated with negative child adjustment.

The following sections present the findings of the current study in relation to the existing research literature.

\section{Findings and Research Literature: Part 1}

Parents of gifted children reported using a directive yet flexible parenting style, as their main parenting style. They reported using a parenting style that is high on the control, expectations, 
warmth, and communication dimensions. This authoritative parenting style has been shown to be linked to positive child adjustment (Kaufmann, Gesten, Lucia, Salcedo, Rendina-Gobioff, \& Gadd, 2000). The same parents reported using less of the authoritarian parenting style which has been linked to negative child adjustment (Chen, Dong, \& Zhou, 1997; Dekovic \& Janssens, 1992; Thompson, Hollis, \& Richards, 2003). Finally, the least reported parenting style used by these parents is the permissive parenting style, also associated with negative child adjustment (Williams, Degnan, Perez-Edgar, \& Henderson, 2009). When mothers and fathers of gifted children were compared, mothers were significantly more authoritative than fathers.

These results concur with the Snowden and Christian (1999) study but differ from the results of Cornell and Grossberg (1987). The Snowden and Christian study had similar parent demographics to those in the present study: middle aged (in their 40s), most were married, highly educated, and English-speaking. Snowden and Christian concluded that parents of gifted children did not enforce rigid rules and allowed children to make appropriate decisions. Parents in their study spent a lot of time with their children, playing and reading, and encouraging creativity. Although these parenting behaviours are not characterized in the same manner by Baumrind, the traits are consistent with an authoritative parenting style.

On the other hand, Cornell and Grossberg (1987) found parents of gifted children used little control (i.e., less emphasis on setting and applying rules and procedures) but were cohesive (i.e., supportive and helpful), expressive (i.e., open to discussion), and intellectually-culturally orientated (i.e., interest in political, social, intellectual, and cultural activities). As with the Snowden and Christian study (1999), the measures used in the Cornell and Grossberg study were not based on Baumrind's parenting styles. Cornell and Grossberg found that parents of gifted children did not put emphasis on rules and procedure (i.e., low control), which points to a more permissive rather than 
authoritative parenting style. In contrast, the current study found a mainly authoritative parenting style in parents of gifted children, characterized by firm control.

Why does this difference exist between Cornell and Grossberg (1987) and the present study? The answer to this is not clear. Both studies had samples of gifted children between 7 and 11 years old and English-speaking highly educated parents. The Cornell and Grossberg study used a different measure to examine the characteristics of the parents. It is perhaps this difference that would explain the divergent results. The Cornell and Grossberg study also found parent reported social, emotional, and somatic adjustment problems, whereas the current study found only parent reported peer social adjustment problems.

As stated above, the present study also found that the perception of child adjustment varied according to the different participants. Cornell and Grossberg (1987) measured the adjustment levels of gifted children from the perspective of the parents, teachers, and children and found similar discrepancies. They found that parents reported gifted children as being less well-adjusted but neither the teachers nor the gifted children reported any adjustment problems. The researchers proposed that there may be significant differences in the perception of child adjustment. Based on the findings of the present study as well as those of Cornell and Grossberg, this issue warrants further inquiry.

The main question of this study was to examine if parenting styles play a role in gifted children's adjustment. Based on these results, it can be deduced that parenting style does not necessarily explain why certain gifted children may experience peer social problems. Arriving at this finding is fundamental to moving forward in order to find out what may explain parent reported peer social problems in gifted children. 
Other interesting findings emerged from the correlation analyses. Authoritative parenting style reported by mothers was related to more conduct problems in gifted children identified with peer social problems. The authoritarian parenting style reported by mothers was related to fewer conduct problems in gifted children identified with no peer social problems. These results stand in contrast to a number of findings on parenting styles in the general child population. In particular, the results contradict previous research findings about authoritarian parenting style and conduct problems (Thompson, Hollis, \& Richards, 2003). The present results nevertheless show that the use of a parenting style seems to contribute in the increase or decrease in these types of behaviours. It is evident then that these findings require further investigations in future studies.

As for fathers of gifted children, the authoritarian parenting style was found to be associated with higher overall negative adjustment in gifted children identified with peer social problems, thus confirming the literature on parenting styles (Chen, Dong, \& Zhou, 1997; Dekovic \& Janssens, 1992; Thompson, Hollis, \& Richards, 2003). In both mothers and fathers, however, the permissive parenting style was found to be related to lower self-concept scores as reported by the gifted children. This result also supports previous findings on permissive parenting style and child adjustment (Williams, Degnan, Perez-Edgar, \& Henderson, 2009).

While this study did not establish a relationship between the use of a parenting style and the presence of peer social problems, it demonstrated that parenting style does have an influence on the adjustment of gifted children. Although these associations were found, the actual mean scores of the adjustment problems were not borderline or abnormal for gifted children. The correlations do, however, show that there is an association between the use of a parenting style and the presence conduct problems and higher or lower child self-concept. In summary, these results indicate some support to the literature that proposes that parenting is an important contributor to child adjustment 
(Deater-Deckard, 2000; Kiff, Lengua, \& Zalewski, 2011; Maccoby, 1992; 2000; Morris, Silk, Steinberg, Sessa, Avenevoli, \& Essex, 2004).

\section{Findings and Research Literature: Part 2}

Although the main purpose of this study was to examine the parenting of gifted children in relation to adjustment problems, an additional research objective was to compare the adjustment levels of gifted and nongifted children in order to confirm previous comparative studies. In line with what most studies had indicated about gifted children (Bracken \& Brown, 2006; Metha \& McWhirter, 1997), this study found that gifted children do well, sometimes better than nongifted children in certain areas.

The results show that according to fathers and teachers, nongifted children experience more problems such as hyperactivity and emotional problems. Nongifted children, however, reported more general feelings of happiness and satisfaction with life. Again it is important to note that as in the gifted sample, discrepancies were found between the reports of the various participants. It appears then that the issue of perception of adjustment levels is present whether the children are gifted or nongifted.

In light of the comparative findings, the view which proposes that gifted children are just as well-adjusted as nongifted children (Kitano \& Lewis, 2005) is supported. Nevertheless, a group of gifted children were reported to have peer social problems, confirming empirical and clinical studies which pointed to a group of gifted children experiencing adjustment difficulties (Benony, Van der Elst, Chahraoui, Benony, \& Marnier, 2007; Parker, 1996; Sankar-DeLeeuw, 2004).

Furthermore, parenting styles were compared between parents of gifted and nongifted children to detect if they use different parenting styles. In the present study, both sets of parents 
reported similar use of the three parenting styles. They reported using a predominantly authoritative parenting style, less of an authoritarian parenting style and even less of a permissive parenting style.

In addition, the parenting styles between mothers and fathers of nongifted children were compared. Both mothers of gifted and nongifted children reported using more of an authoritative parenting style than the fathers. In short, the parenting style profile is similar between parents of gifted and nongifted children.

Lastly, this study compared the relationships between parenting styles and adjustment problems between the parents of the gifted and nongifted children in order to see whether the findings corresponded to those of the literature on parenting styles. In the nongifted sample, the authoritative parenting style was associated with fewer conduct problems, thus confirming the findings of previous studies. In addition, both the authoritarian and the permissive parenting styles were found to be associated with children's lower self-concept. These results are also in line with studies on parenting styles. It is only with mothers of gifted children that the relationships between authoritarian and authoritative parenting styles and child outcomes are not in accord with the parenting literature.

\section{Alternative Explanations}

According to some parents, gifted children experience peer social problems. Before discussing these results in detail, it would be important to clarify what the term "peer" signified in this study. The sample herein was composed of gifted children who were not part of a separate gifted class or program at school. All the gifted children were in classrooms with children who were approximately the same chronological age but not necessarily gifted. Outside of school, gifted children could have interacted with children of different ages and abilities, but most of their time 
would have been spent with same age peers. This could have an impact of the social behaviour of gifted children, in that they were not necessarily exposed to children who were also gifted.

Parenting style was not found to be a contributor to having peer social problems. What other factors would explain the reported presence of peer social problems? Assuming that parents' perceptions were accurate, why then would one group of gifted children have peer social problems and another not? A lack of social skills would be an explanation. This study, however, found that the children had prosocial behaviours in the normal range. Perham (2013) also demonstrated that gifted children appear to have appropriate social skills. Neither gender, nor IQ, nor parenting styles nor demographics provide an explanation.

What other factors could explain these results? The answer may lie in individual character differences. A predisposition to certain personality traits, such a perfectionism or excitability, can be an explanation. Nugent (2000) suggested that gifted children can be overly perfectionist, which would in turn affect their relationship with their families and friends. Pfeiffer and Stocking (2000) proposed that some gifted children might display high levels of excitability. They can be passionate, energetic, and interested in several subjects at the same time. Gifted children with peer social problems may display such characteristics. Furthermore, some gifted children could be buffered by a trait such as that of resiliency (Kitano \& Lewis, 2005). As a result, gifted children who are more resilient may not be affected by problems with their peers.

An interesting finding of the present study was that for mothers, authoritarian parenting was linked to fewer conduct problems and higher intellectual self-concept, whereas authoritative parenting style was linked to more conduct problems in gifted children. Why this contradiction with previous studies on parenting styles and specifically that of Cornell and Grossberg (1987)? Gifted children are cognitively different than nongifted children, thus the associations between parenting 
styles and child adjustment could be different. The difference in the results may also lie in the definitions of parenting traits and behaviours, the current study being based on Baumrind's work and that of Cornell and Grossberg being based on a scale developed by Moos and Moos (1981). It is evident then that closer examination of each of Baumrind's dimensions, that of control, warmth, communication, and expectation, in relation to gifted child adjustment, is essential to bring clarity to the different findings.

It is possible that specific characteristics in the authoritarian parenting style, as opposed to the authoritative parenting style, better suit the needs of some gifted children. The difference between these two styles lies mainly in the warmth and communication dimensions, which the authoritarian parenting style has less of (Baumrind, 1966). In addition, the difference between these two parenting styles is not only in degree but in the composition of the dimensions. For example, Baumrind (1996) brought specification for the communication dimension explaining that authoritarian and authoritative parents differ in the type of communication. It may be that gifted children adjust better when the mother uses an authoritarian communication style. Authoritarian parents tend to use a position centered communication style that focuses on legitimizing their role and authority. An example of this would be a parent saying to their child that their decision in a certain situation is final. Authoritative parents tend to use a person centered communication style which establishes their parental authority through persuasion. An example of this would be the parent explaining that in such a situation (e.g., choosing an appropriate activity), the mother is the best person to decide. Could it be that gifted children benefit from a more position centered style when communicating with a child that has advanced cognitive skills? An authoritative mother who is occupied with several daily tasks may have a difficult time handling arguments and justifications from her gifted child. Perhaps using parts of an authoritarian communication style may help the 
gifted child better adapt within their social and family environment. Based on the results of this current study, it is unclear which type of dimension would lead to positive adjustment for gifted children.

In addition, the literature on parenting behaviour has further specified the level of control found in authoritarian parenting into two types of controls, that is psychological and behavioural control (Schaefer, 1965). Psychological control implies that the parent directs and manipulates how the child thinks. Behavioural control consists of the parent directing how the child behaves. Parental psychological control has been shown to be associated with maladaptive outcomes, such as an increase of depressive and antisocial behaviour in adolescents (Barber, Stolz, \& Olsen, 2005) and externalizing behaviours in children (Aunola \& Nurmi, 2005). Parental behavioral control has been connected to positive adjustment, such as a decrease in antisocial and externalizing behaviour in adolescents (Barber et al., 2005) and young children (Aunola \& Nurmi, 2005). What would be interesting to know is if behavioural control has the same effect in young gifted children and on what type of child adjustment outcome. Also, it would be highly useful to clarify if this effect would be present in both mothers and fathers of gifted children. Based on the results of the current study, it appears that gifted children benefit from firmer control from mothers.

As for the lack of interrater agreement, both parents agreed on the adjustment levels of their child. This lends support to the validity of parent perception of child adjustment. Nevertheless, the question remains as to why parents and teachers disagreed. It is possible that children's behaviour may be contextual. Peer social problems may arise mostly outside classroom situations, in contexts where parents are witnesses to these problems. Also, environmental factors can influence children's behaviours, such as the size and composition of a social group. How a child behaves in a classroom of 30 children versus one or two at home or elsewhere can vary. In addition, parents and teachers 
potentially have different expectations of children's behaviour, with parents expecting more from their child in terms of social interactions.

This, however, does not explain why gifted children themselves did not report low popularity scores on the PHSCS-2. Could it be that parents perceive a preference of being alone and getting along better with adults as negative behaviours? The gifted child could just prefer to associate with older children and adults. The notion of gifted children preferring to work alone has been investigated by French, Walker and Shore (2011). The researchers surveyed 247 gifted youth from ages 8 to 18 who were part of associations for the gifted. The children were asked open and close ended questions about their preferred learning style and conditions, interests in activities and their perceived support received in learning situations. Most gifted youth indicated a preference to working alone, however, this varied on the learning context. Gifted youth who felt that their work was appreciated and felt their learning needs and levels were supported had a strong preference to work with others. Sankar-DeLeeuw (2004) also noted a tendency to play alone in case studies of four gifted children. It is plausible that some gifted children might be content to play and work alone or limit their interactions, which could explain the PHSCS-2 scores.

\section{Limitations and Strengths}

As with all studies, certain limitations exist and must be addressed, such as sample size. A larger sample size would lend strength to the results, in particular to the correlational analysis. Likewise, by having a larger sample size, there would be a greater chance to have a more representative sample of the gifted child population and consequently a larger sample of gifted children with adjustment problems. This sample was limited since the participants were Englishspeaking and culturally homogenous with most of the parents having completed university studies. 
The gifted benchmark used in this study also posed limitations in the composition of the sample. Authors such as Gardner (1983) consider that there is more than one type of intelligence. Perhaps using a larger criterion for establishing giftedness, such as a standardized test and performance tests in different domains like arts and music, would allow for a more varied sample.

Another limitation is the use of self-report questionnaires for measuring adjustment levels and parenting styles. These types of questionnaires are dependent on the respondents' ability to honestly report adjustment levels and parenting style. For the PAQ-R questionnaire, it is possible parents reported their desired parenting styles rather than the one actually used. This could be due to the bias of social desirability, in that the parents answered the PAQ-R in a manner that would be favorably viewed by the researcher. Most parents in this study were highly educated, and thus it is possible they reported using more authoritative traits knowing from various sources that it is deemed the most "appropriate" parenting style. This could also be a possible contributor to the low alpha coefficients found in the authoritative subscale of the PAQ-R.

It is also important to note that correlational analyses were used in order to establish possible relationships between parenting styles and child adjustment. The analyses do not allow for causal inferences between the variables. Thus, it is not possible to state that certain parenting styles cause adjustment issues in gifted children. This study did, however, show that such a relationship is present and consequently one of the factors that could influence the gifted child's adjustment.

The present study examined parenting style as being a possible link to the adjustment in young gifted children, which has not been done by previous studies. It is also the only study on gifted children that measured parenting styles directly based on Baumrind's theoretical and empirical work. This study also provided information on the parenting of gifted children, and provided information not only on maternal but also on paternal parenting styles. Finally, this study 
gathered several perspectives on child adjustment. Mothers and fathers agreed on the adjustment levels of their child, while teachers and children disagreed with the parents. This information opens up further investigations into the perception of adjustment in gifted children.

In addition, as shown in the literature review, the majority of studies on gifted children have focused on confirming whether gifted children had higher or lower adjustment levels compared to nongifted children rather than looking closely at a sample of gifted children. The current study confirmed the findings of previous studies, but also revealed a group of gifted children that the parents say have difficulties with their peers.

In sum, the current study brought important information to the overall body of literature concerning the parenting styles of parents of gifted children in relation to adjustment problems. Firstly, parents of gifted children said they use a mostly authoritative parenting style. This study also found that several parents said that their gifted child experience peer social problems, although the children and teachers did not report this adjustment problem. Furthermore, parenting style was not found to be a contributor to this particular adjustment problem. In addition, it was found that authoritarian parenting style in mothers of gifted children is related to positive child outcomes (i.e., fewer conduct problems and a higher intellectual self-concept) and authoritative parenting style in mothers of gifted children is related to a negative child outcome (i.e., more conduct problems).

The study of gifted children, particularly if a specific group is having difficulties, is essential. It is important to note that in constructing the cut-off scores for the SDQ, Goodman determined that $20 \%$ of the child population would have borderline to abnormal scores. The present study found a higher rate of parent reported peer social problems in gifted children: $39.5 \%$. Ignoring adjustment problems can lead to even greater adjustment difficulties in later years (Kupersmidt \& Coie, 1990), therefore having broader negative consequences on the potential and contribution of 
gifted children in our society. The results of the present study provided important information to parents, educators, clinicians, and researchers to better understand and optimize the functioning of this child population, specifically with their peers. Greater attention can be brought to this area of their lives. In that sense, the support system of gifted children can help by providing them with different social opportunities, for example, outside of their school activities, in order to develop and foster peer relations with children with similar abilities.

\section{Future Directions}

The results of this study give rise to suggestions for furthering knowledge about gifted children. For example, to make the measurement of adjustment levels and parenting styles more objective, future studies should include observational methods in addition to self-report measures. Observations of child and parent behaviours would help to determine which aspects of Baumrind's dimensions may be playing a role in gifted children's adjustment.

Observations of gifted children and their peer interactions have been done using qualitative methods on very small samples of gifted children (Reis \& Renzulli, 2004; Sankar-DeLeeuw, 2004). Future empirical studies should examine the social interactions of gifted children using larger sample sizes with measurements such as those used by Kasari, Locke, Gulsrud and Rotheram-Fuller (2011). This would help determine whether peer social problems emanate from certain personal characteristics or are a product of the interaction between gifted and nongifted children. Sandstrom, Zakriski and Kupersmidt (2004) stated that peer interactions occur within a transactional model. The transactional model in child development posits that children's self-perceptions and behaviours have a reciprocal influence on each other. 
Considering that the present study found that parents reported peer social problems in several gifted children, it would be informative to explore parent perceptions and expectations of gifted children and relate them to peer social problems using qualitative or even mixed-method approaches. Approaches, such as ones used by Ross (1985) and Morawska and Sanders (2009), would be useful to gather additional information. Also, versions of the same measures that parents, teachers, and children could complete should be developed in order to permit a more direct comparison of child adjustment and parenting styles between the responders.

Future studies should investigate gifted child personality traits and temperament, as well as other parent-child interactions, to see if they are possible contributors to adjustment problems and specifically to that of peer social problems. 


\section{References}

Achenbach, T. M., \& Rescorla, L. A. (2001). Manual for the ASEBA School-Age Forms \& Profiles. Burlington, VT: University of Vermont, Research Center for Children, Youth \& Families.

Aunola, K., \& Nurmi, J. E. (2005). The role of parenting styles in children's problem behavior. Child Development, 76, 1144-1159.

Baker, J. A. (1995). Depression and suicidal ideation among academically gifted adolescents. Gifted Child Quarterly, 39, 218-223.

Barber, B. K., Stolz, H. E., \& Olsen, J. A. (2005). Parental support, psychological control, and behavioural control: Assessing relevance across time, culture and method. Monographs of the Society for the Research in Child Development, 70(4), 282.

Barnett, L. A., \& Fiscella, J. (1985). Child by any other name... A comparison of the playfulness of gifted and nongifted children. Gifted Child Quarterly, 29, 61-66.

Bartell, N. P., \& Reynolds, W. M. (1986). Depression and self-esteem in academically gifted and nongifted children: A comparison study. Journal of School Psychology, 24, 55-61.

Baumrind, D. (1966). Effects of authoritative control on child behavior. Child Development. $37,887-907$.

Baumrind, D. (1967). Child care practices anteceding 3 patterns of preschool behaviour. Genetic Psychology Monographs, 75, 43-88.

Baumrind, D. (1968a). Authoritarian vs. authoritative parental control. Adolescence, 3(11), 255.

Baumrind, D. (1968b). Manual for the Preschool Behavior Q Sort. (Parental Authority Research Project) Berkeley, CA: University of California Press.

Baumrind, D. (1971). Current patterns of parental authority. Developmental Psychology Monograph, 4, 1-103. 
Baumrind, D. (1991). The influence of parenting style on adolescent competence and substance use. Journal of Early Adolescence, 11, 56-95.

Baumrind, D. (1996). The discipline controversy revisited. Family Relations, 45, 405-414.

Baumrind, D., Larzelere, R. E., \& Owens, E. B. (2010). Effects of preschool parents' power assertive patterns and practices on adolescent development. Parenting: Science and Practice, $10,157-201$.

Baumrind, D. (2012). Differentiating between confrontive and coercive kinds of parental power assertive disciplinary practices. Human Development, 55, 35-51.

Benony, H., Van Der Elst, D., Chahraoui, K., Benony, C., \& Marnier, J. P. (2007). Lien entre dépression et estime de soi scolaire chez les enfants intellectuellement précoces. L'Encéphale, 22, 11-20.

Bills, R. E. (1975). A system for assessing affectivity. University of Alabama Press, Tuscaloosa, AL. Bourdon, K. H., Goodman, R., Rae, D. S., Simpson, G., \& Koretz, D. S. (2005). The Strengths and Difficulties Questionnaire: U.S. normative data and psychometric properties. Journal of the American Academy of Child \& Adolescent Psychiatry, 44, 557-564.

Bracken, B. A., \& Brown, E. F. (2006). Behavioral identification and assessment of gifted and talented students. Journal of Psychoeducational Assessment, 24, 112-122.

Buri, J. R. (1989, May). An instrument for the measurement of Parental Authority Prototypes. Paper presented at the $61^{\text {st }}$ Annual Meeting of the Midwestern Psychological Association, Chicago, IL.

Buri, J. R. (1991). Parental authority questionnaire. Journal of Personality Assessment, 57, 110119. 
Cattell, R. B. (1960). Culture Fair Intelligence Test 2. Chapaign, IL: Institute for Personality and Ability Testing.

Chang, H. J., \& Kuo, C. C. (2013). Overexcitabilities: Empirical studies and application. Learning and Individual Differences, 23, 53-63.

Chao, R. K. (2001). Extending research on the consequences of parenting style for Chinese Americans and European Americans. Child Development, 72,1832-1843.

Chen, X., Dong, Q., \& Zhou, H. (1997). Authoritative and authoritarian parenting practices and social and school performance in Chinese children. International Journal of Behavioural Development, 21, 855-873.

Clark, L. A., \& Watson, D. (1995). Constructing validity: Basic issues in objective scale development. Psychological Assessment, 7, 309-319.

Cohen, J. (1988). Statistical power analysis for the behavioral sciences (2nd ed.). Hillsdale, NJ: Erlbaum.

Coie, J. D., \& Dodge, K. A. (1983). Continuities and changes in children's social status: A fiveyear longitudinal study. Merrill-Palmer Quarterly, 29, 261-282.

Cooley, E., \& Ayres, R. (1988). Cluster scores for the Piers-Harris Children's Self-Concept Scale: Reliability and independence. Educational and Psychological Measurement, 48, 1019-1024.

Coopersmith, S. (1981). Self-esteem inventories. Palo Alto, CA: Consulting Psychologists Press.

Coopersmith, S., \& Gilbert, R. (1982). Behavioral Academic Self-Esteem (BASE): A rating scale. Palo Alto, CA: Consulting Psychologists Press.

Cornell, D. G., \& Grossberg, I. W. (1987). Family environment and personality adjustment in gifted program children. Gifted Child Quarterly, 31, 59-64. 
Crick, N. R., \& Dodge K. A. (1994). A review and reformulation of social information- processing mechanisms in children's social adjustment. Psychological Bulletin, 115, 74-101.

Deater-Deckard, K. (1998). Parenting stress and child adjustment: Some old hypotheses and new questions. Clinical Psychology: Science and Practice, 5, 314-332.

Deater-Deckard, K. (2000). Parenting and child behavioral adjustment in early childhood:

A quantitative genetic approach to studying family processes. Child Development, 71, 468484.

Dekovic, M., \& Janssens, J. M. (1992). Parents' child-rearing style and child's sociometric status. Developmental Psychology, 28, 925-932.

Derogatis, L. R. (1993). BSI Brief Symptom Inventory: Administration, scoring, and procedures manual. Minneapolis, MN: National Computer Systems.

DiPerna, J. C. (2005). Review of the Cognitive Abilities Test, Multilevel Edition, Form 6. In R. A. Spies \& B. S. Plake (Eds.), The sixteenth mental measurements yearbook (pp. 228-234). Lincoln, NE: University of Nebraska.

Dwairy, M. (2004). Parenting styles and mental health of Arab gifted adolescents. Gifted Child Quarterly, 48, 275-286.

Dwairy, M., Achoui, M., Abouserie, R., \& Farah, A. (2006). Parenting styles, individuation, and mental health of Arab adolescents: A third cross-regional research study. Journal of CrossCultural Psychology, 37, 262-272.

Ehlers, B., Ehlers, T., \& Makus, H. (1978). Marburg Behaviour Checklist MBC. Göttingen, Germany: Hogrefe. 
Ehlers, T. (1981). Questionnaire scales for assessing environment and behaviour of children by parents. Berichte aus dem Fachbereich Psychologie, Philipps-Universitat.

Forsyth, P. (1987). A study of self-concept, anxiety, and security of children in gifted, French immersion, and regular classes. Canadian Journal of Counseling, 21, 153-156.

Franklin, M. R., Duley, S. M., Rousseau, E. W., \& Sabers, D. L. (1981). Construct validation of the Piers-Harris Children's Self Concept Scale. Educational and Psychological Measurement, $41,439-443$.

French, L. R., Walker, C. H., \& Shore, B. M. (2011). Do gifted children really prefer to work alone? Roeper Review, 30, 145-159.

Gallagher, J. J. (1990). Editorial: The public and professional perception of the emotional status of gifted children. Journal for the Education of the Gifted, 13, 202-211.

Gardner, H. (1983). Frames of mind: The theory of multiple intelligence. New York: Basic Books.

Goodman, R. (1997). The Strengths and Difficulties Questionnaire: A research note. Journal of Child Psychology and Psychiatry, 38, 581-586.

Goodman, R. (1999). Comparing the Strengths and Difficulties Questionnaire and the Child Behavior Checklist: Is small beautiful? Journal of Abnormal Child Psychology, 27, 17-24.

Goodman, R. (2001). Psychometric properties of the Strengths and Difficulties Questionnaire. Journal of the American Academic of Child and Adolescent Psychiatry, $40,1337-1345$.

Grapko, M. F. (1975). Institute of Child Study Security Test. Toronto, Ontario, Canada: Institute of Child Study.

Hagmann-von Arx, P., Meyer, C. S., \& Grob, A. (2008). Assessing intellectual giftedness with the WISC-IV and the IDS. Journal of Psychology, 216, 172-179. 
Hamuda, M. A., \& Imam, I. A. (1996). The Psychological State Scale for adolescents and adults [In Arabic]. Cairo, Egypt: Dar El Fekr El Arabi.

Harter, S. (1981). A new self-report scale on intrinsic versus extrinsic orientation in the classroom: Motivational and informational components. Developmental Psychology, 17, $300-312$.

Harter, S. (1982). The Perceived Competence Scale for Children. Child Development, 53, 87-97. Henmon, G., \& Nelson, M. J. (1973). Henmon-Nelson Tests of Mental Ability. Boston, MA: Houghton Mifllin.

Hollingworth, L. S. (1942). Children above 180 IQ: Their origins and development. New York: World Book.

Jumper, R. L. (2010). Gifted children's communication about bullying: Understanding the experience. (Doctoral dissertation, Texas A\&M University, 2010). Dissertation Abstracts International Section A: Humanities and Social Sciences, 71(3-A), 771.

Kasari, C., Locke, J., Gulsud, A., \& Rotheram-Fullum, E. (2011). Social networks and friendships at school: Comparing children with and without ASD. Journal of Autism and Developmental Disorders, 41, 533-544.

Kaufmann, D., Gesten, E., Lucia, R. C. S., Salcedo, O., Rendina-Gobioff, G., \& Gadd, R. (2000). The relationship between parenting style and children's adjustment: The parents'perspective. Journal of Child and Family Studies, 9, 231-245.

Kiff, C. J., Lengua, L. J., \& Zalewski, M. (2011). Nature and nurturing: Parenting in the context of child temperament. Clinical Child and Family Psychology Review, 14, 251-301. 
Kitano, M. K., \& Lewis, R. B. (2005). Resilience and coping: Implications for gifted children and youth at risk. Roeper Review, 27, 200-205.

Kupersmidt, J. B., \& Coie, J. D. (1990). Preadolescent peer status, aggression, and school adjustment as predictors of externalizing problems in adolescence. Child Development, 61, $1350-1362$.

Lachar, D. (1982). Personality Inventory for Children (PIC): Revised format manual supplement. Los Angeles, CA: Western Psychological Services.

Landis, J. R., \& Koch, G. G. (1977). The measurement of observer agreement for categorical data. Biometrics, 33, 159-17.

Leaverton, L., \& Herzog, S. (1979). Adjustment of the gifted child. Journal for the Education of the Gifted, 2, 149-152.

LeBuffe, P. A., Shapiro, V. B., \& Naglieri, J. A. (2009). The Devereux Student Strengths Assessment. Lewisville, NC: Kaplan.

Lehman, E. B., \& Erdwins, C. J. (1981). The social and emotional adjustment of young intellectually-gifted children. Gifted Child Quarterly, 25, 134-137.

Lieberman, J. N. (1977). Playfulness: Its relationship to imagination and creativity. New York, NY: Academic Press.

Lipsitt, L. P. (1958). Self-concept scale for children. In K. Corcoran \& J. Fischer (Eds.), Measures for clinical practice: A sourcebook. (Vol. 1, 3rd ed., pp. 617-618). New York, NY: Free Press.

Liratni, M., \& Pry, R. (2011). Enfants à haut potentiel intellectuel: Psychopathologie, socialisation et comportements adaptatifs. Neuropsychiatrie de l'enfance et de l'adolescence, 699, 1-9. 
Loeb, R. C., \& Jay, G. (1987). Self-concept in gifted children: Differential impact in boys and girls. Gifted Child Quarterly, 31, 9-14.

Lohman, D. F., \& Hagen, E. P. (2001). Cognitive Abilities Test (Form 6). Itasca, IL: Riverside.

Lopez, V., \& Sotillo, M. (2009). Giftedness and social adjustment: Evidence supporting the resilience approach in Spanish-speaking children and adolescents. High Abilities Studies, 20, $39-53$.

Ludwig, G., \& Cullinan, D. (1984). Behavior problems of gifted and nongifted elementary school girls and boys. Gifted Child Quarterly, 28, 37-39.

Maccoby, E. E. (1992). The role of parents in the socialization of children: A historical overview. Developmental Psychology, 28, 1006-1017.

Maccoby, E. E. (2000). Parenting and its effects on children: On reading and misreading behavior genetics. Annual Review of Psychology, 51, 1-27.

Martin, L. T., Burns, R. M., \& Schonlau, M. (2010). Mental disorders among gifted and nongifted youth: A selected review of the epidemiologic literature. Gifted Child Quarterly, 54, 31-41.

Merz, F. (1983). The Teacher Behaviour Checklist LEBO. Interner Bericht. Marburg: Fachbereich Psychologie, Phlipps-Universität .

Metha, A., \& McWhirter, E. H. (1997). Suicide ideation, depression, and stressful events among gifted adolescents. Journal for the Education of the Gifted, 20, 284-304.

Michalchio, S. P., \& Solomon, C. R. (2002). The relationship between older and newer parenting categories and child behaviour. American Journal of Orthopsychiatry, 72, 401-414. 
Moos, R. H., \& Moos, B. S. (1981). Family Environment Scale manual. Palo Alto, CA:

Consulting Psychologists Press.

Moss, E. (1990). Social interaction and metacognitive development in gifted preschoolers. Gifted Child Quarterly, 34, 16-20.

Morawska, A., \& Sanders, M. R. (2009). Parenting gifted and talented children: Conceptual and empirical foundations. Gifted Child Quarterly, 53, 163-173.

Morris, A. S., Silk, J. S., Steinberg, L., Sessa, F. M., Avenevoli, S., \& Essex, M. J. (2004).

Temperamental vulnerability and negative parenting as interacting predictors of child adjustment. Journal of Marriage and Family, 64, 461-471.

Muris, P., Meesters, C., \& van den Berg, S. (2003). The Strengths and Difficulties Questionnaire (SDQ): Further evidence for its reliability and validity in a community sample of Dutch children and adolescents. European Child \& Adolescent Psychiatry, 12, 1-8.

Neihart, M. (1999). The impact of giftedness on psychological well-being: What does the empirical literature say? Roeper Review, 22, 10-17.

Nowicki, S., \& Strickland, B. R. (1973). A locus of control scale for children. Journal of Consulting and Clinical Psychology, 40, 148-155.

Nugent, S. A. (2000). Perfectionism: Its manifestations and classroom-based interventions. Journal of Secondary Gifted Education, 11, 215-221.

O’Connor, K. J. (2005). Stereotypes and beliefs regarding intellectually gifted students: Perceptions of pre-service school counselors. Unpublished doctoral dissertation. University of Connecticut, Storrs-Mansfield.

Olweus, D. (1996). The Revised Olweus Bully/Victim Questionnaire. Bergen, Norway: HEMIL Center, University of Bergen. 
Otis, A. S., \& Lennon, R. T. (1969). Otis-Lennon Mental Ability Test: Technical handbook. New York, NY: Harcourt, Brace \& World.

Parker, W. D. (1996). The psychological adjustment of mathematically gifted children. Gifted Child Quarterly, 40, 154-157.

Perham, H. J. (2013). Interpersonal skills of gifted students: Risk versus resilience. Unpublished doctoral dissertation, Arizona State University, Arizona.

Pfeiffer, S. I., \& Stocking, V. B. (2000). Vulnerabilities of academically gifted children. Special Services in the Schools, 6, 83-93.

Piechowski, M. M. (1999). Overexcitabilities. Encyclopedia of Creativity, 2, 325-334.

Piers, E. V., \& Harris, D. B. (1964). Age and other correlates of self-concept in children. Journal of Educational Psychology, 55, 91-95.

Piers, E. V., Harris, D. B., \& Herzberg, D. S. (2002). The Piers-Harris Children's Self Concept Scale-Second Edition. Los Angeles, CA: Western Psychological Services.

Piers, E. V., \& Herzberg, D. H. (2002). Piers-Harris Children's Self-Concept Scale, Second Edition manual. Los Angeles, CA: Western Psychological Services.

Platten, M. R., \& Williams, L. R. (1981). Replication of a test-retest factorial validity study with the Piers-Harris Children's Self Concept Scale. Educational and Psychological Measurement, $41,453-462$.

Querido, J. G., Warner, T. D., \& Eyberg, S. M. (2002). Parenting styles and child behaviour in African-American families of preschool children. Journal of Clinical Child Psychology, 31, 272-277.

Reis, S. M., \& McCoach, D. B. (2000). The underachievement of gifted students: What do we know and where do we go? Gifted Child Quarterly, 44, 152-169. 
Reis, S. M., \& Renzulli, J. S. (2004). Current research on the social and emotional development of gifted and talented students: Good news and future possibilities. Psychology in the Schools, $41,119-130$.

Reitman, D., Rhode, P. C., Hupp, S. D. A., \& Altobello, C. (2002). Development and validation of the Parental Authority Questionnaire - Revised. Journal of Psychopathology and Behavioral Assessment, 24, 119-127.

Renzulli, J. S. (1978). What makes giftedness? Reexamining a definition. Moravia, NY: Chronicle Guidance Publications.

Reynolds, C. R., \& Bradley, M. (1983). Emotional stability of intellectually superior children versus nongifted peers as estimated by chronic anxiety levels. School Psychology Review, 12, 190-194.

Reynolds, C. R., \& Paget, K. D. (1983). National normative and reliability data for the revised Children's Manifest Anxiety Scale. School Psychology Review, 132, 324-336.

Reynolds, C. R., \& Richmond, B. O. (1985). The revised-children's manifest anxiety scale. Los Angeles, CA: Western Psychological.

Richards, J., Encel, J., \& Shute, R. (2003). The emotional and behavioral adjustment of intellectually gifted adolescents: A multi-dimensional, multi-informant approach. High Ability Studies, 14, 153-164.

Roid, G. H. (2003). Stanford-Binet Intelligence Scale, Fifth Edition (SB5). Itasca, IL: Riverside. Rosenberg, M. (1965). Society and the adolescent self-image. Princeton, NJ: Princeton University Press.

Ross, L. (1984). Concerns of parents of gifted children. Unpublished doctoral dissertation. McGill University, Montreal, Quebec, Canada. 
Rost, D. H., \& Czechlik, T. (1994). The psycho-social adjustment of gifted children in middlechildhood. European Journal of Psychology of Education, 9, 15-25.

Rowan, M. (1985). North York Self-Concept Inventory (revised norms). North York, Ontario, Canada: North York Board of Education.

Rudasill, K. M., Adelson, J. L., Callahan, C. M., Houlihan, D. V., \& Keizer, B. M. (2013). Gifted students' perceptions of parenting styles: Associations with cognitive ability, sex, race, and age. Gifted Child Quarterly, 57, 15-24.

Sandstrom, M. J., Zakriski, A. L., \& Kupersmidt, J. B. (2004). Understanding the experience of peer rejection. In Dodge, Kenneth A. (Ed), Children's peer relations: From development to intervention: Decade of behavior. Washington, DC: American Psychological Association: 101-118.

Sankar-DeLeeuw, N. (2004). Case studies of gifted kindergarten children: Profiles of promise. Roeper Review, 26, 192.

Schaefer, E. S. (1965). Children's reports of parental behavior: An inventory. Child Development, $36,413-424$.

Schneider, B. H., Clegg, M. R., Byrne, B. M., Ledingham, J. E., \& Crombie, G. (1989). Social relations of gifted children as a function of age and school program. Journal of Educational Psychology, 81, 48-56.

Scholwinski, E., \& Reynolds, C. R. (1985). Dimensions of anxiety among high IQ children. Gifted Child Quartely, 29, 125-130.

Seligman, M. E., \& Csikszentmihalyi, M. (2000). Positive psychology: An introduction. American Psychologist, 55, 5-14. 
Slicker, E. K. (1998). Relationship of parenting style to behavioral adjustment in graduating high school seniors. Journal of Youth and Adolescence, 27, 345-372.

Snowden, P. L., \& Christian, L. G. (1999). Parenting the young gifted child: Supportive behaviours. Roeper Review, 21, 215-221.

Solomon, D., Kendall, A. J., \& Oberlander, M. I. (1976) Children's social attitude and value scales. In O. G. Johnson (Ed.), Tests and measurements in child development (Vol. 2). San Francisco, CA: Jossey Bass: 1074-1075.

Sparrow, S. S., Balla, D., \& Cicchetti, D. V. (1984). Vineland Adaptive Behavior Scales: Interview edition, expanded form. Circle Pines, MA: American Guidance Service. Speilberger, C. (1973). State-Trait Anxiety Inventory for Children. Palo Alto, CA:

Consulting Psychologists Press.

Sternberg, R. J. (1985). Beyond IQ: A triarchic theory of human intelligence. New York, NY: Cambridge University Press.

Stevens, J. P. (2002). Applied multivariate statistics for the social sciences. Mahwah, NJ: Lawrence Erlbaum Associates.

Storm, R. (1984). Parent as a teacher inventory and manual. Bensenville, IL: Scholastic Testing. Sun, G. (2005). The use of Piers-Harris Children's Self-Concept Scale to measure the multidimensional structural model of self-concept for children in second grade (Doctoral dissertation, University of Iowa, 2005). Dissertations Abstracts International, 67(1), 96.

Terman, L. M. (1925-1959). Genetic studies on genius. Vol I-V. Standford, CA: Standford University Press.

Thompson, A., Hollis, C., \& Richards, D. (2003). Authoritarian parenting attitudes as a risk for conduct problems. European Child \& Adolescent Psychiatry, 12, 84-91. 
Thorndike, R. L., \& Hagen, E. (1978). Cognitive Abilities Test CAT. Atlanta, GA: Houghton Mifflin.

Thorndike, R. L., \& Hagen, E. (1982). Canadian Cognitive Abilities Test. Scarborough, Ontario, Canada: Nelson Canada.

Thorndike, R. L., Hagen, E., \& Sattler, M, (1986). Technical manual, Stanford-Binet Intelligence Scale: Fourth Edition. Chicago, IL: Riverside.

Thorpe, L. P., Clark, W. W., \& Tiegs, E. W. (1953). California Test of Personality. Monterey, CA: McGraw-Hill.

Tong, J., \& Yewchuk, C. (1996). Self-concept and sex-role orientation in gifted high school students. Gifted Child Quarterly, 40, 15-23.

Vallerand, R. J., Gagné, F., Senécal, C., \& Pelletier, L. G. (1994). A comparison of school intrinsic motivation and perceived competence of gifted and regular students. Gifted Child Quartely, 38, 172-175.

Wechsler, D. (1974). Manual for the Wechsler Intelligence Scale for Children-Revised. New York, NY: Psychological Corporation.

Wechsler, D. (1991). The Wechsler Intelligence Scale for Children-Third edition. San Antonio, TX: The Psychological Corporation.

Wechsler, D. (2001). Wechsler Individual Achievement Test - Second Edition. San Antonio, TX: The Psychological Corporation.

Wechsler, D. (2003). Wechsler Intelligence Scale for Children-Fourth Edition. San Antonio, TX: The Psychological Corporation.

Whitmore, J.R. (1980). Giftedness, conflict and underachievement. Boston, MA: Allyn and Bacon. Wierczerkowski, W., Nickel, A., Janowski, A., Fittkau, B., \& Rauer, W. (1974). Anxiety 
Questionnaire for Children. Braunschweig, Germany: Westermann.

Williams, L. R., Degnan, K. A., Perez-Edgar, K. E., \& Henderson, H. A. (2009). Impact of behavioral inhibition and parenting style on internalizing and externalizing problems from early childhood through adolescence. Journal of Abnormal Child Psychology, 37(8), 1063.

World Health Organisation. (2010). ICD-10 Classifications of Mental and Behavioural Disorder: Clinical descriptions and diagnostic guidelines. Geneva, Switzerland: World Health Organisation.

Jung, C. G. (1954). The gifted child. In H. Read, M. Fordham, \& G. Adler (Eds.), The collected works of C. G. Jung (Vol. 17). New York, NY: Pantheon Books. 


\section{APPENDIX A}

\section{Parent Consent Form}


Research project: Parenting style and adjustment in gifted children

Researcher: Vassiliki Pilarinos, doctoral student, Department of psychology, University of Montreal

Research directors: C. R. Solomon-Scherzer, Ph.D., Department of psychology, University of Montreal and Linda S. Pagani, Ph.D., Department of Psychoeducation, University of Montreal

$\mathrm{Ms} / \mathrm{M}$,

You have been selected to participate in a study that aims to determine the adjustment levels of bright and gifted children and the parenting styles used by parents of bright and gifted children. However, before signing the consent form, it is important that you attentively read the following information and that you ask questions in order to fully understand what your participation involves.

\section{PROJECT DESCRIPTION}

This project's purpose is to determine if there is a particular parenting style parents use with bright and gifted children. Secondly, some bright and gifted children can face difficult challenges such as high levels of anxiety and social isolation due to their special abilities. The project will seek to find out if there is a relationship between these difficulties and a specific parenting style.

\section{PROCEDURE}

Your participation involves an at-home face-to-face interview with a researcher (2h) during which you will fill in two questionnaires concerning your child's behaviour and your parenting style. During the same interview, your child will complete or respond to one questionnaire about his or her self-concept and an intelligence quotient test (IQ test).

\section{ADVANTAGES INCONVENIENTS}

By participating in this research, you can contribute to the understanding of bright and gifted children and their adjustment. However, by participating in this research, and talking about your parenting style and your child's adjustment, it is possible that you and/or your child might experience some feelings of anxiety. If that occurs, do not hesitate to speak to the researcher. She can refer you to an appropriate resource.

\section{WITHDRAWAL FROM THE STUDY}

You and your child's participation in this study is fully voluntary and may be interrupted at any given time without any negative consequences. If you or your child decide to stop your participation in the study, any information gathered from you will be destroyed.

\section{CONFIDENTIALITY}

The researchers have taken different measures to ensure the greatest confidentiality:

- Files are kept in locked cabinets which are in an office assigned especially for this study.

- The use of a password in order to access computerized information.

- Names will be replaced by codes to ensure confidentiality.

- Data from publications will present information in group averages and will not relate to any individual. 
Computerized information is preserved in an anonymous data bank for 7 years.

For any questions or concerns about your participation, you can reach Vassiliki Pilarinos at and by email: or C. R. Solomon-Scherzer at and by

email:

Any complaint about your participation in this study can be addressed to the University of Montreal ombudsman at or by email: . (Long distance calls are covered by the ombudsman).

CONSENT

After all my questions have been answered, and having understood the purpose, inconveniences and advantages of the study, I freely agree to participate in this study and consent that my child also participate. I understand that we are free to withdraw at any time from the study without the need to justify our decision.

Name of parent/guardian:

NAME

LAST NAME

Signature of parent/guardian:

Name of child:

NAME

LAST NAME

I certify that a) I explained the terms and conditions of the present consent form to the participant signing this document b) I answered the questions that were asked regarding this consent form; c) I clearly indicated that he/she is free to drop-out of the study at any time.

Name of researcher

Signature Date




\section{APPENDIX B \\ Demographic Questionnaire}


Date:

Last name:

First name:

Phone: Home

Work:

Mobile:

Email:

Your age:

Your gender: $\square$ Male $\square$ Female

Your child's name: Your child's gender: $\square$ Male $\square$ Female

Name of your child's teacher(s):

Name of your child's school:

1. Which language do you speak at home? If more than one, which one do you speak most often?

1. English

2. French

3. Italian

4. German

5. Greek

6. Chinese

7. Polish

8. Arabic

9. Other

2. What is your civil status?

1. Married and living with partner

2. Living in a permanent relationship with a partner but without being married

3. Separated (legally or not) and not living with a partner

4. Divorced and not living with a partner

5. Widowed and not living with a partner

6. Never married but lived in a permanent relationship with a partner in the past

7. Never married and never lived with a partner

3. What is the highest level of education that you have completed?

1. Elementary school

2. Partial studies in high school

3. High school

4. Partial studies in a private commercial college, a technical institute, a CEGEP, nursing school

5. Diploma or certificate from a private commercial college, a technical institute, a CEGEP, nursing school

6. Partial studies in university

7. Bachelors degree, Masters degree or Doctorate completed 
4. How many children under 18 years old live in your home? 


\section{APPENDIX C}

\section{Teacher Consent Form}


Research project: Parenting style and adjustment in gifted children

Researcher: Vassiliki Pilarinos, doctoral student, Department of psychology, University of Montreal

Research directors: C. R. Solomon-Scherzer, Ph.D., Department of psychology, University of Montreal and Linda S. Pagani, Ph.D., Department of Psychoeducation, University of Montreal

$\mathrm{Ms} / \mathrm{M}$,

You have been selected to participate in a study that aims to determine the adjustment levels of children with different intellectual levels. However, before signing the consent form, it is important that you attentively read the following information and that you ask questions in order to fully understand what your participation involves.

\section{PROJECT DESCRIPTION}

This project's purpose is to determine if there is a particular parenting style parents use with bright children. Secondly, some bright children can face difficult challenges such as high levels of anxiety and social isolation due to their special abilities. The project will seek to find out if there is a relationship between these difficulties and a specific parenting style.

\section{PROCEDURE}

Your participation involves completing one questionnaire concerning your students' behaviour. The questionnaire takes approximately 5 minutes to complete.

\section{ADVANTAGES INCONVENIENTS}

By participating in this research, you can contribute to the understanding of bright children and their adjustment. However, by reporting your student's adjustment, it is possible that you might experience some feelings of anxiety. If that occurs, do not hesitate to speak to the researcher. She can refer you to an appropriate resource.

\section{WITHDRAWAL FROM THE STUDY}

Your participation in this study is fully voluntary and you may interrupt the process at any given time without any negative consequences. If you decide to stop your participation in the study, any information gathered from you will be destroyed.

\section{CONFIDENTIALITY}

The researchers have taken different measures to ensure the greatest confidentiality:

- Files are kept in locked cabinets which are in an office assigned especially for this study.

- The use of a password in order to access computerized information.

- Names will be replaced by codes to ensure confidentiality.

- Data from publications will present information in group averages and will not relate to any individual.

Computerized information is preserved in an anonymous data bank for 7 years. 
For any questions or concerns about your participation, you can reach Vassiliki Pilarinos at and by email: or C. R. Solomon-Scherzer at and by

email:

Any complaint about your participation in this study can be addressed to the University of Montreal ombudsman at or by email: . (Long distance calls are covered by the ombudsman).

\section{CONSENT}

After all my questions have been answered, and having understood the purpose, inconveniences and advantages of the study, I freely agree to participate in this study. I understand that I am free to withdraw at any time from the study without the need to justify my decision.

Name of teacher:

NAME

LAST NAME

Signature of participant:

Name of school:

Email:

I certify that a) I explained the terms and conditions of the present consent form to the participant signing this document b) I answered the questions that were asked regarding this consent form; c) I clearly indicated that he/she is free to drop-out of the study at any time.

Name of researcher

Signature

Date 


\section{APPENDIX D}

Sample WISC-IV Item 


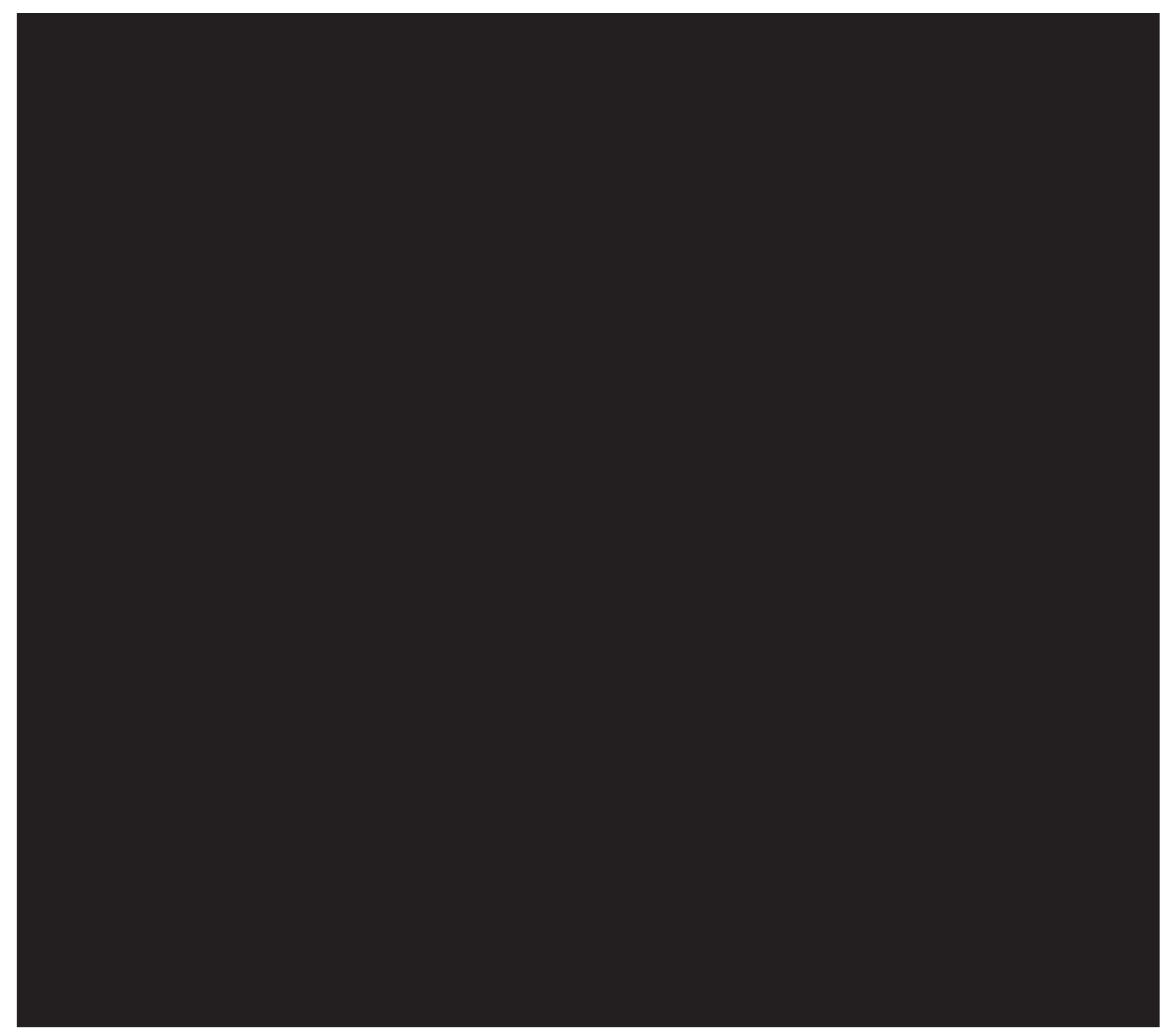




\section{APPENDIX E}

Parental Authority Questionnaire-Revised 


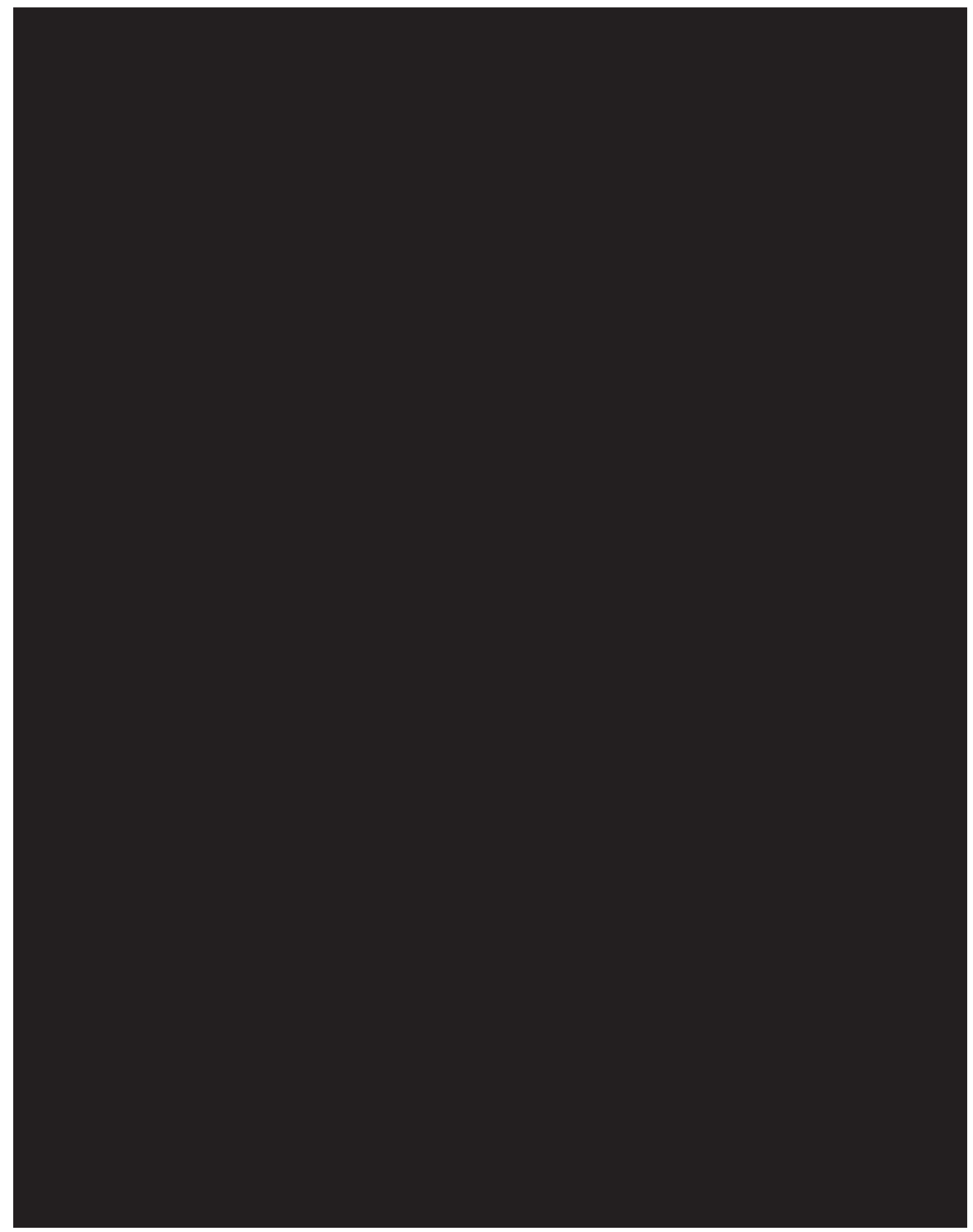




\section{APPENDIX F}

Strengths and Difficulties Questionnaire 


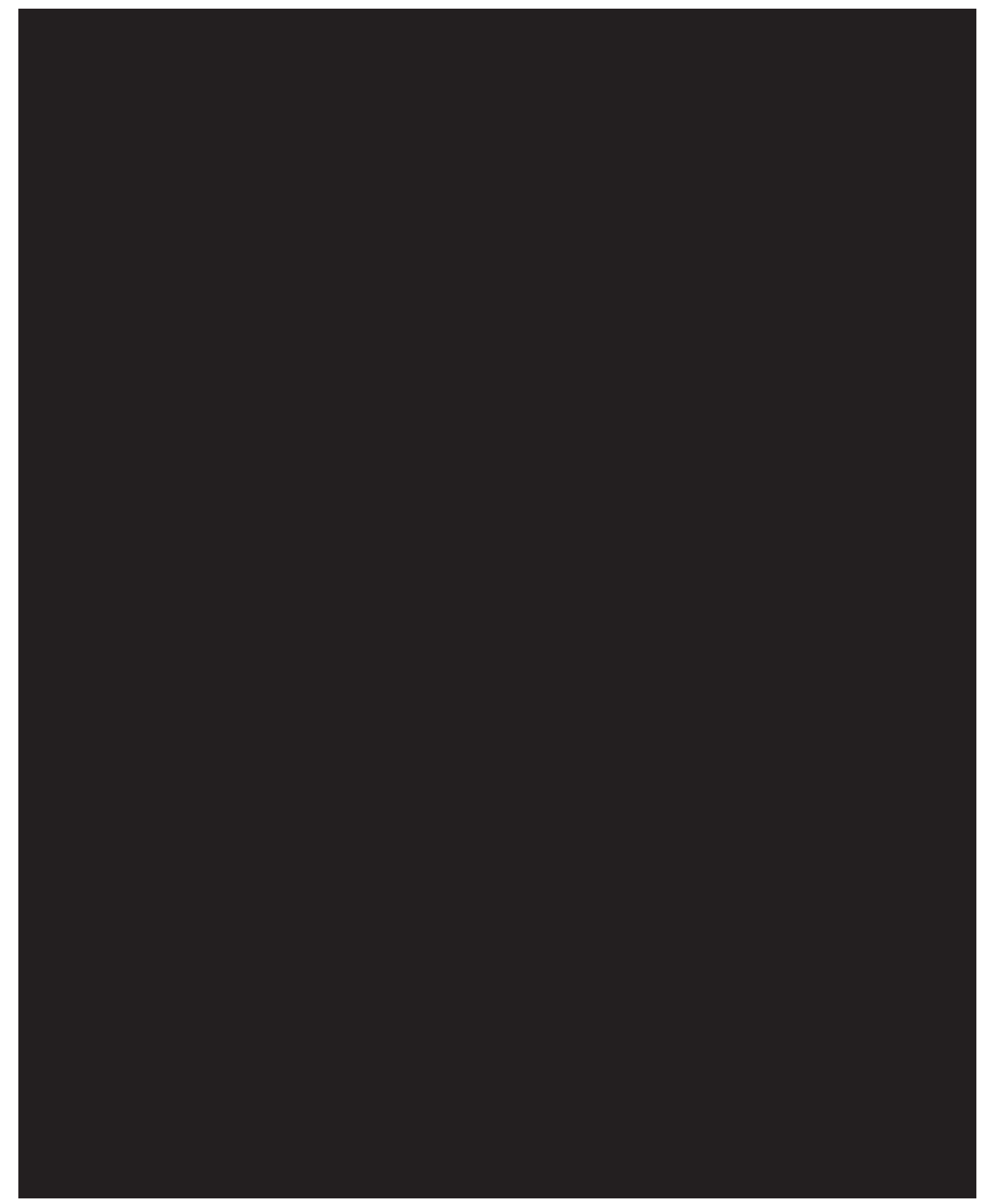




\section{APPENDIX G}

\section{Piers-Harris Self-Concept Scale-Second Edition}




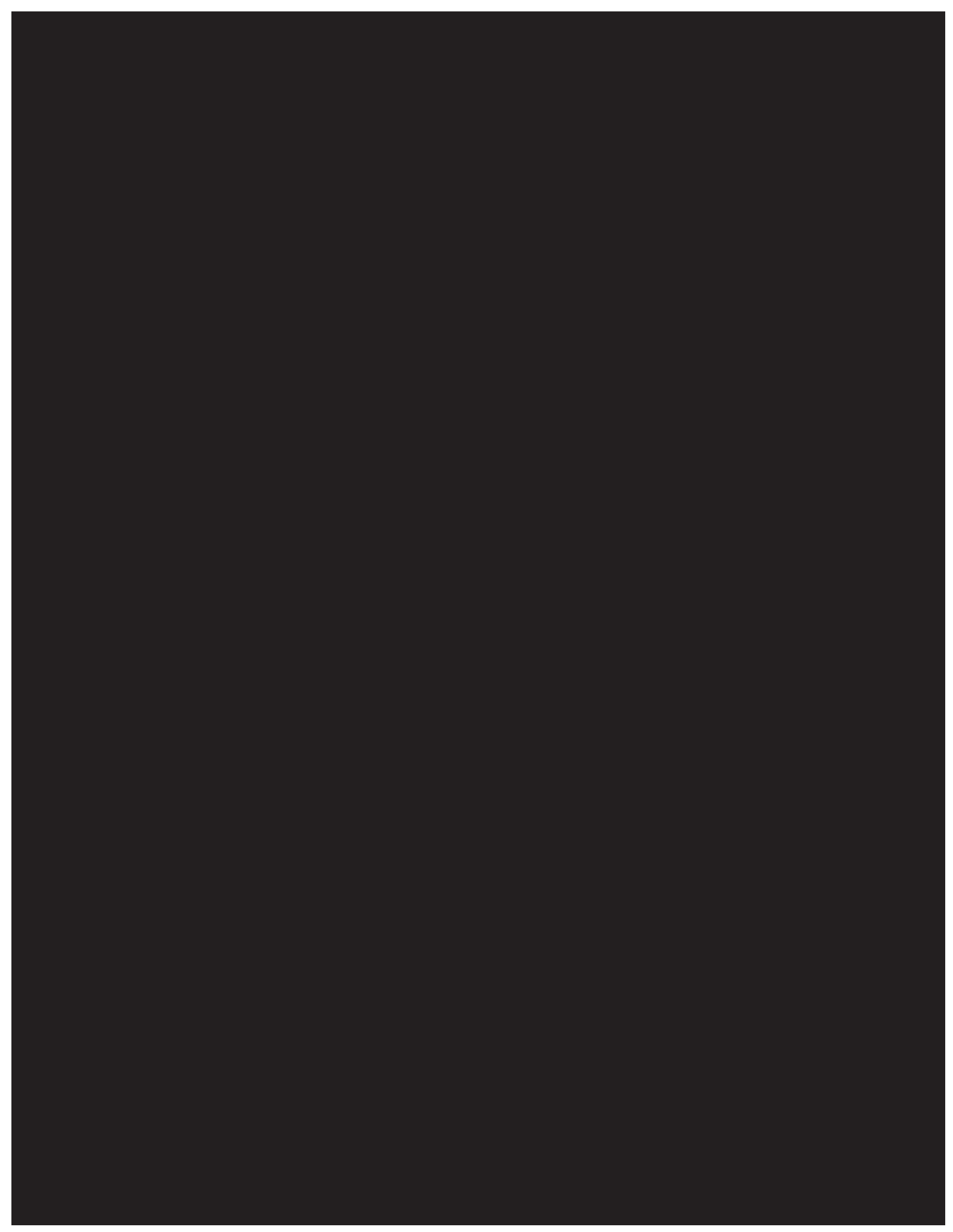




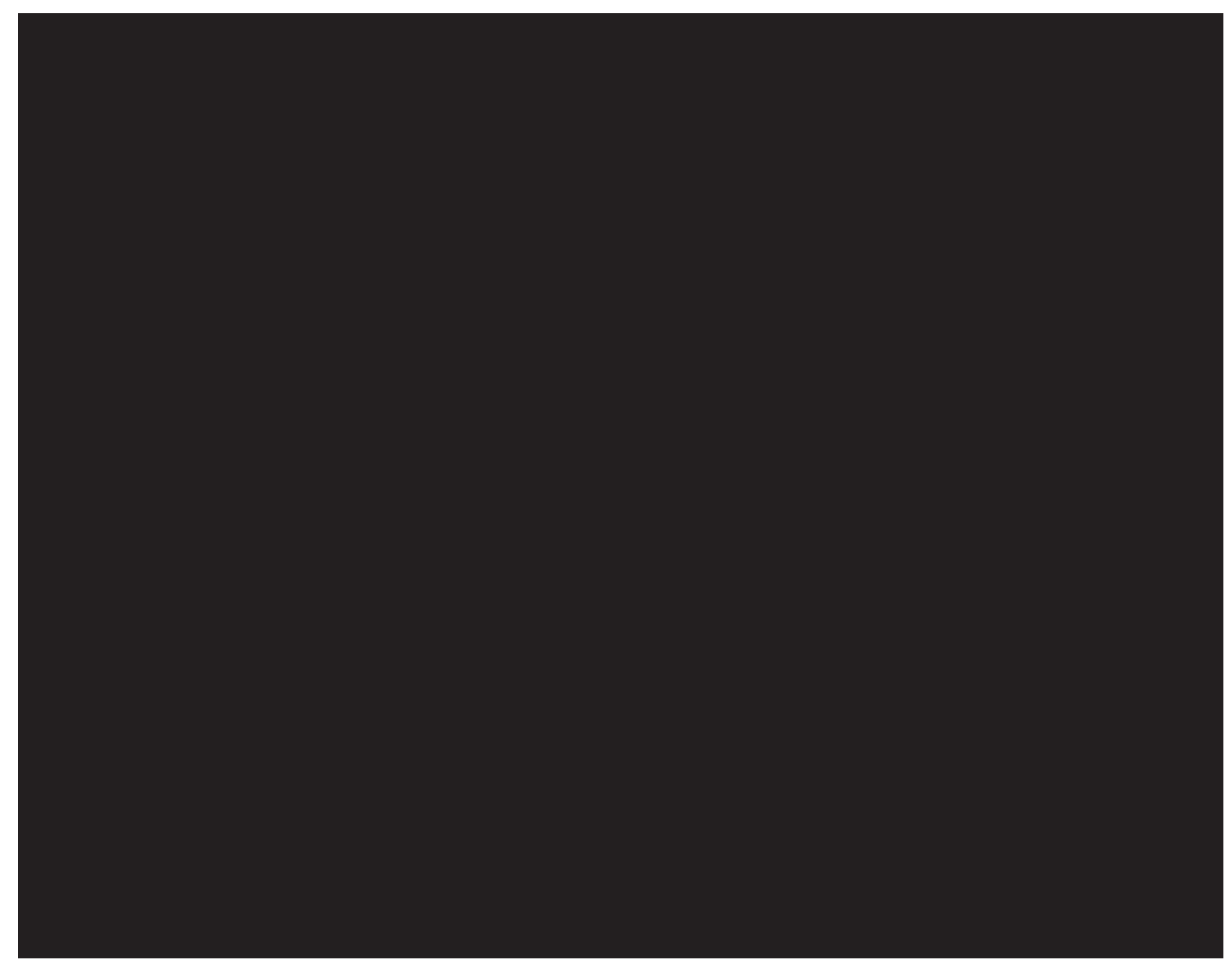


